\title{
Predictability of a Stepwise Shift in Pacific Climate during the Late 1990s in Hindcast Experiments Using MIROC
}

\author{
Yoshimitsu CHIKAMOTO, Masahide KIMOTO \\ Atmosphere and Ocean Research Institute, The University of Tokyo, Kashiwa, Japan \\ Masayoshi ISHII \\ Japan Agency for Marine-Earth Science and Technology, Yokohama, Japan \\ Meteorological Research Institute, Tsukuba, Japan \\ Masahiro WATANABE \\ Atmosphere and Ocean Research Institute, The University of Tokyo, Kashiwa, Japan \\ Toru NOZAWA \\ National Institute for Environmental Studies, Tsukuba, Japan
}

Takashi MOCHIZUKI, Hiroaki TATEBE, Takashi T. SAKAMOTO, Yoshiki KOMURO

Japan Agency for Marine-Earth Science and Technology, Yokohama, Japan

\section{Hideo SHIOGAMA}

National Institute for Environmental Studies, Tsukuba, Japan

Masato MORI, Sayaka YASUNAKA, Yukiko IMADA

Atmosphere and Ocean Research Institute, The University of Tokyo, Kashiwa, Japan

Hiroshi KOYAMA, Masato NOZU

Japan Agency for Marine-Earth Science and Technology, Yokohama, Japan

and

Fei-fei JIN

Department of Meteorology, University of Hawaii at Manoa, Honolulu, Hawaii, USA

(Manuscript received 8 March 2011, in final form 22 July 2011)

Corresponding author: Yoshimitsu Chikamoto, Atmo-

sphere and Ocean Research Institute, The University

of Tokyo, 5-1-5, Kashiwanoha, Kashiwa, Chiba 277-

8568, Japan.

E-mail: chika44@aori.u-tokyo.ac.jp

(C) 2012, Meteorological Society of Japan 


\begin{abstract}
Sea surface temperature (SST) predictability in the Pacific on decadal timescales is examined in hindcast experiments using the coupled atmosphere-ocean model MIROC with low, medium, and high resolutions. In these hindcast experiments, initial conditions are obtained from an anomaly assimilation procedure using the observed oceanic temperature and salinity while prescribing natural and anthropogenic forcing based on the IPCC concentration scenarios. Our hindcast experiments show the predictability of SST in the western subtropical Pacific, the Indian Ocean, and the tropics to the North Atlantic. Previous studies have examined the SST predictability in the Indian Ocean and the Atlantic, but SST predictability in the western subtropical Pacific has not been evaluated. In the western Pacific, the observed SST anomalies in the subtropics of both hemispheres increased rapidly from the early 1990s to the early 2000s. While this SST warming in the western subtropical Pacific is partly explained by global warming signals, the predictions of our model initialized in 1995 or 1996 tend to simulate the pattern of the SST increase and the associated precipitation changes. This large climate change around the late 1990s may be related to phenomena such as the recent increase in the typhoon frequency in Taiwan and the weakened East Asian monsoon reported by recent studies.
\end{abstract}

\section{Introduction}

Future climate prediction associated with global warming has received much attention because political decisions are needed in order to solve socioeconomic problems arising from climate change (Hibbard et al. 2007; Cox and Stephenson 2007). In the Intergovernmental Panel on Climate Change (IPCC) Fourth Assessment Report (AR4), the global warming trend in the 20th century was successfully simulated by coupled climate models as a response to natural and anthropogenic forcing such as greenhouse gas and aerosol concentrations, solar cycle variations, and major volcanic eruptions. The globally averaged temperature trend in the next century is evaluated by the coupled climate models that are prescribed by the future concentration scenarios in the IPCC AR4. However, predictions of regional climate change in the next decades are desired by decision makers in order to assess the social and economical impacts on agriculture, water resources, an flood risk management (Meehl et al. 2009).

To predict regional climate change on decadal timescales, we consider the internal variation involved in atmospheric and oceanic variability as well as the externally forced component related to global warming. The former and the latter are considered initial and boundary value problems, respectively. Hawkins and Sutton (2009) showed that uncertainties in initial conditions dominate the overall uncertainty of the prediction in lead times of less than 10 years (i.e., in initial value problems), whereas climate predictions on timescales of a century are much less sensitive to initial conditions (i.e., they are boundary value problems). By initial- izing the ocean state with a prescribed external forcing, a recent series of studies has successfully predicted regional climate changes on decadal timescales under global warming (Smith et al. 2007; Keenlyside et al. 2008; Pohlmann et al. 2009; Mochizuki et al. 2010; Chikamoto et al. 2011). The predictive skill is mainly affected by internal variability on decadal timescales.

Decadal climate variability sometimes takes the form of stepwise changes, called climate regime shifts. One of the most famous changes is the mid1970s shift (Nitta and Yamada 1989; Trenberth 1990; Tanimoto et al. 1993; Mantua et al. 1997; Zhang et al. 1997; Minobe 1999; Yasunaka and Hanawa 2002). Recently, some studies reported a climate shift in atmospheric and oceanic variables in the late 1990s over the North Pacific. Tu et al. (2009) showed that the typhoon frequency near Taiwan abruptly increased from the late 1990s to the early 2000s. Kim et al. (2011) indicated that an inter-seasonal fluctuation of summer precipitation over the Korean peninsula had a regime shift during the mid-1990s, which is associated with changes in the East Asian summer monsoon. In the Tibetan Plateau, the surface temperature suddenly increased during the late 1990s, which affected a rapid Tibetan glacier retreat (Xu et al. 2009). Minobe (2002) described a rapid increase in sea surface temperature (SST) and upper water heat storage in the Central North Pacific and the Kuroshio-Oyashio extension region and a rapid cooling in the Eastern North Pacific during the late 1990s. Consistent with the SST change in the North Pacific, a northward shift of the coastal Oyashio was also observed around 1995 (Yasuda 2003; Tatebe and Yasuda 2005). 


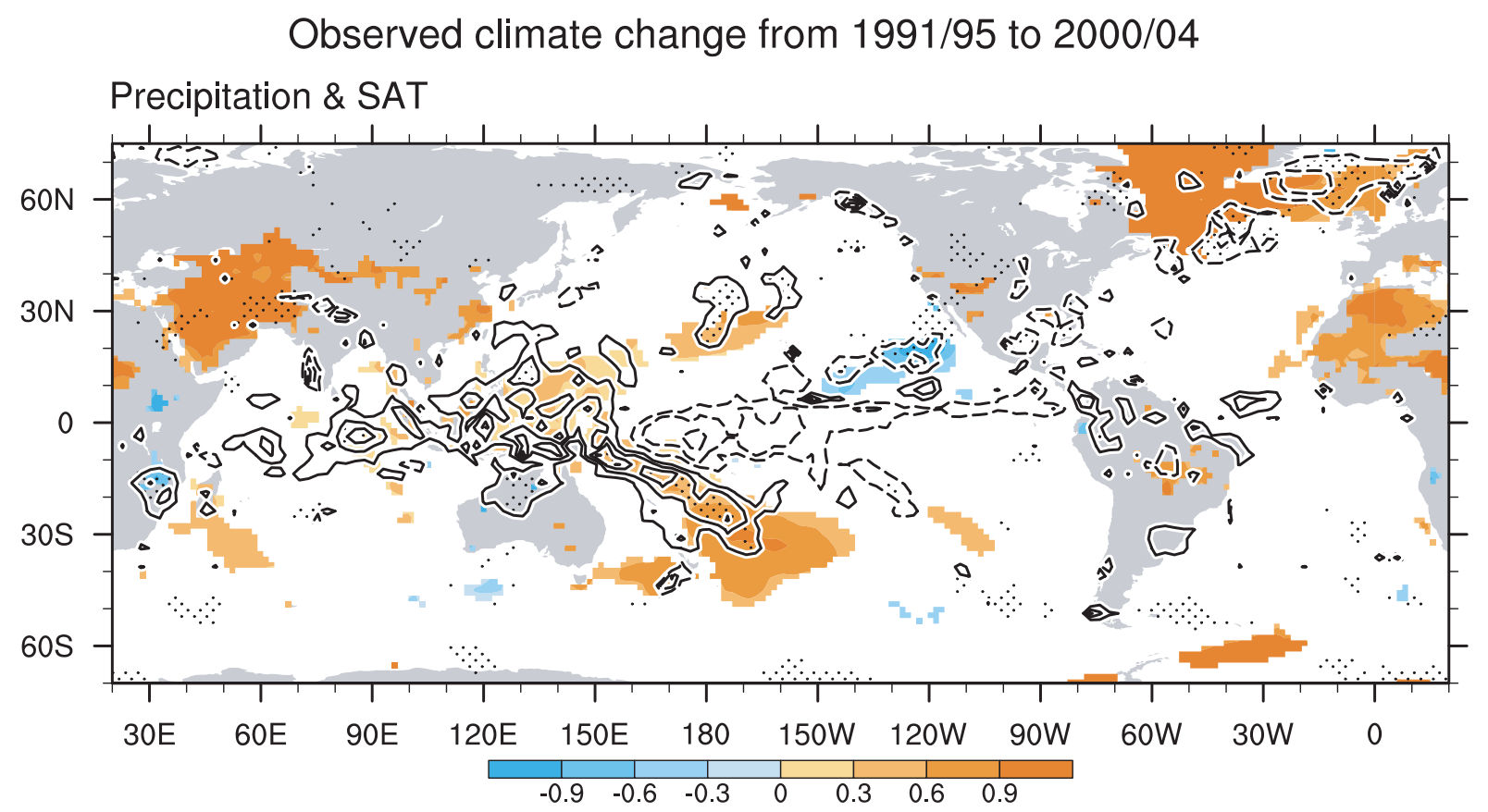

Fig. 1. Observed difference map between the 1991-1995 and 2000-2004 means. Shading and contours indicate surface air temperature $(0.3 \mathrm{~K}$ interval $)$ and precipitation $\left(0.5 \mathrm{~mm} \mathrm{day}^{-1}\right.$ interval $)$. Negative contours are dashed and the zero contours are omitted. Shaded region in the surface air temperature and stippled region in precipitation indicate areas exceeding the thresholds for significance at the $90 \%$ level. Statistical significance is calculated on a yearly basis using a two-tailed Student's t-test. Observational datasets of precipitation and surface air temperature are those of Global Precipitation Climatology Project (GPCP) (Adler et al. 2003) and ERA-Interim (Berrisford et al. 2009).

These stepwise changes during the late 1990s accompanied basin-scale climate change in the Pacific. Figure 1 shows the observed changes in surface air temperature and precipitation from the 1991-1995 period to the 2000-2004 period. A significant increase in surface air temperature is observed in the western tropical Pacific, with horseshoe like shape, and west of the Tibetan Plateau. Although the precipitation changes over the Korean peninsula reported by Kim et al. (2011) are not very significant in Fig. 1 because of seasonality, an atmospheric response to the enhanced precipitation around the Maritime Continent can affect monsoon variability. Moreover, significant changes in surface air temperature and precipitation occur in the South Pacific. The enhanced precipitation in the Maritime Continent is consistent with the work of Hsu and Chen (2011).

In the present study, we examine the predictability of climate change during the late 1990s in hindcast experiments using the coupled climate model, the Model for Interdisciplinary Research on Climate (MIROC). Hindcast experiments are performed using three versions of MIROC: low, medium, and high resolution models. Since different coupled climate models simulate somewhat different changes in climate (Hawkins and Sutton 2009), it is worthwhile to investigate the multi model ensemble experiments. Although the experimental design and model physics are not identical in the three experiments as described in Section 2, robust results for climate change during the late 1990s are obtained at all resolutions of MIROC.

The rest of this paper is organized as follows. Section 2 describes the model and experiments. A model climate drift during prediction is also reported in this section. In Section 3, we evaluate the predictability in the western subtropical Pacific and examine the stepwise climate change during the late 1990s. The predictable component of this climate shift evaluated using our model simulations is discussed in Section 4. We conclude the paper in Section 5 . 


\section{Model and experiments}

\subsection{Model}

The coupled atmosphere-ocean general circulation model (MIROC) adopted here was cooperatively developed by Atmosphere and Ocean Research Institute of the University of Tokyo, National Institute for Environmental Studies (NIES), and Japan Agency for Marine-Earth Science and Technology. MIROC's atmospheric general circulation model (AGCM) is based on a global spectral dynamical core and a standard physics package (K-1 Model Developers 2004) developed at the Center for Climate System Research (CCSR)/NIES/Frontier Research Center for Global Change (FRCGC). The ocean general circulation model is the CCSR Ocean Component model (COCO; Hasumi 2006), which includes a sea ice model. No flux correction is applied in exchanging heat, water, and momentum fluxes between the atmosphere and ocean. A land model that incorporates a river module is also coupled.

As summarized in Table 1, we use different versions of MIROC: MIROC $3 \mathrm{~m}$, MIROC4h, and MIROC5. In MIROC3m (hereafter referred to as LOW), the atmospheric and oceanic components are a T42 spectral model with 20 levels on vertical $\delta$-coordinates and approximately $1^{\circ}$ longitudelatitude grid with 44 vertical levels, respectively. MIROC4h (referred to as HI) includes the same model physics as MIROC $3 \mathrm{~m}$ but at an eddypermitting resolution: a T213 spectral model with 56 levels in the atmosphere and an approximately $1 / 4^{\circ} \times 1 / 6^{\circ}$ longitude-latitude grid with 47 vertical levels in the ocean. In MIROC5 (referred to as MID), most parts of the model, except for the atmospheric dynamical core, are updated or even replaced with new parameterization schemes from MIROC $3 \mathrm{~m}$ and MIROC4h. The resolution of MIROC5 is T85 spectral with 40 levels in the atmosphere and approximately $1^{\circ}$ horizontal grid of curvilinear coordinates with 49 vertical levels in the ocean. Details of the performance and settings of the LOW, MID, and HI models are described in Nozawa et al. (2007), Watanabe et al. (2010), and Sakamoto et al. (2011).

\subsection{Experiment}

To evaluate the decadal climate predictability, we perform the following three experiments using all resolution versions of MIROC: the 20th century climate simulation (NoAS), the data assimilation (ASSM), and the hindcast (HCST) experiments. In the NoAS experiment, the model is prescribed by the historical natural and anthropogenic forcing such as greenhouse gas and aerosol concentrations, solar cycle variations, and major volcanic eruptions and the future concentration scenarios based on the IPCC report. Using a model climatology defined by the NoAS experiment, the observed temperature and salinity anomalies in the ocean are incorporated into the model anomalies by an incremental analysis update (IAU) scheme (Bloom et al. 1996; Huang et al. 2002) in the ASSM experiment. The observed temperature and salinity anomalies obtained from a gridded monthly objective analysis produced by Ishii et al. (2006) and Ishii and Kimoto (2009) are linearly interpolated to each day and to the ocean model grid. An analysis increment estimated from a temporally and spatially invariant model-to-observation ratio of analysis errors is incorporated into the model as constant forcing in the model tendency equation during an analysis interval of one day. Under the current limited computational resources, our simple assimilation approach can be applied to decadal climate prediction. On the basis of the ASSM experiment, we obtain a pair of atmospheric and oceanic initial conditions and perform ensemble HCST experiments. As described below and summarized in Tables 2 and 3, the experimental designs and the number of ensemble members are different among the LOW, MID, and HI models because of the limited computational resources. Details of the model experiment and assimilation procedure are described in Tatebe et al. (2011) and Mochizuki et al. (2011).

Table 1. Summary of MIROC versions.

\begin{tabular}{lllll}
\hline Name & Model & Atm. res. & Ocn. res. & Reference \\
\hline \hline LOW & MIROC3m & T42L20 & $1^{\circ} \times 1^{\circ}$ grid, L44 & Nozawa et al. (2007) \\
MID & MIROC5 & T85L40 & $1^{\circ} \times 1^{\circ}$ grid, L49 & Watanabe et al. (2010) \\
HI & MIROC4h & T213L56 & $1^{\circ} \times 1 / 6^{\circ}$ grid, L47 & Sakamoto et al. (2011) \\
\hline
\end{tabular}


Table 2. Summary of experimental design. First, second, third, fourth, and fifth columns are the model resolution, external forcing, assimilated bottom depth of observational data, assimilation period, and initial conditions in the HCST experiment, respectively.

\begin{tabular}{llccc}
\hline & \multicolumn{1}{c}{ Ext. For. } & Obs. depth & ASSM period & Initial \\
\hline \hline LOW & 20C3M \& A1B & $700-\mathrm{m}$ & $1945-2009$ & Every 5-yr from 1960 \\
MID & 20C3M \& RCP4.5 & $3000-\mathrm{m}$ & $1945-2007$ & Every 5-yr from 1961 \\
HI & 20C3M \& RCP4.5 & $3000-\mathrm{m}$ & $1955-2007$ & Every 5-yr from 1961 \\
\hline
\end{tabular}

Table 3. Number of ensemble members in each experiment. Ensemble members of hindcast experiments in MID and HI are obtained from the lagged averaged forecast (LAF) with the previous three- and six-month lags: initial conditions on July, October, and January 1.

\begin{tabular}{l|cll}
\hline & LOW & \multicolumn{1}{c}{ MID } & \multicolumn{1}{c}{ HI } \\
\hline NoAS & 10 & 3 & 3 \\
ASSM & 10 & 3 & 1 \\
HCST & 10 & $6(\mathrm{LAF})$ & 3 (LAF) \\
\hline
\end{tabular}

The LOW model is based on 10-member ensembles in the NoAS, ASSM, and HCST experiments (Table 3). Nozawa et al. (2005) and Shiogama et al. (2007) performed 10-member ensemble simulations of the 1850-2000 period with the historical data of natural and anthropogenic forcing and of the 2001-2030 period with the A1B-type concentration scenario in the Special Report on Emissions Scenarios (Nakicenovic et al. 2000). These ensemble simulations correspond to the NoAS experiment in the LOW model. From the NoAS experiment, we obtain 10-member initial states on January 1, 1945 and conduct 10-member ensemble assimilations covering 1945-2009. During data assimilation, the observed temperature and salinity anomalies in the upper $700 \mathrm{~m}$ depth are incorporated into MIROC. On the basis of the 10-member assimilation experiment, we perform 10 sets of 11-year-long, 10member ensemble hindcast experiments initialized on January 1 of the years 1960, 1965, 1970, 1975, 1980, 1985, 1990, 1995, 2000, and 2005. These experimental designs in the LOW model are the same as those in Mochizuki et al. (2010) and Chikamoto et al. (2011).

In the MID model, three-member ensemble simulations in the NoAS experiment are performed for 1850-2005 with the historical forcing dataset updated for the Coupled Model Intercomparison
Project-5 (CMIP5) and for 2006-2100 with the concentration scenario of Representative Concentration Pathway (RCP4.5; Moss et al. 2008, 2010). Using the initial conditions on January 1, $1945 \mathrm{ob}-$ tained from the NoAS experiment, the observational temperature and salinity anomalies from the surface to $3000 \mathrm{~m}$ are assimilated into MIROC5 for 1945-2007. The ASSM experiment in the MID model has three ensemble members, whereas the initial conditions in the HCST experiment are currently based on the two ensemble members in the ASSM experiment (the number of ensemble members in the MID model will be increased in the future). In the HCST experiment, we perform 10 sets of 10-year-long, six-member ensemble hindcasts initialized in 1961, 1966, 1971, 1976, 1981, 1986, 1991, 1996, 2001, and 2006. Six ensemble members are obtained from the lagged averaged forecasting (LAF) method with the previous 3- and 6-month lags based on the two-member ASSM experiment. For example, for the 1961 initialization, predictions commenced on July 1, 1960, October 1, 1960, and January 1, 1961.

The experimental design of the HI model is almost the same as that of the MID model. The main differences between these experimental designs are the period in the NoAS and ASSM experiments, the number of ensemble members, and the assimilation procedure. In the HI model, the NoAS experiment has three ensemble members for 1950 2007 but one member for 2008-2035. To reduce the computational cost, the ASSM experiment is conducted with one members for 1950-2007. In the ASSM experiment, we only assimilate the largescale components of observational anomalies into MIROC4h while retaining a small-scale eddy resolved by the HI model's eddy-conserving assimilation (Tatebe et al. 2011).

\subsection{Model climate drift during prediction}

In decadal climate prediction, we need to distinguish climate signals from unrealistic signals arising 
from model drift during prediction. On the basis of a method proposed by INTERNATIONAL CLIVAR PROJECT OFFICE (2011), we estimate the model drift $T_{d r f}$ as follows:

$$
T_{d r f}(\tau)=\frac{1}{N} \sum_{k=1}^{N}\left(T_{p}^{k}(\tau)-T_{a}^{k}(\tau)\right)
$$

where $k=1, \ldots, N$ is the initial time; $\tau$ is the forecast lead time; $T$ is the yearly quantity of interest, for example, temperature and precipitation; and the subscripts $p$ and $a$ represent the ensemble averaged prediction and the corresponding assimilation, respectively. Because of the anomaly assimilation in our system, the model climatological bias is already removed from the model drift in Eq. (1). The observation as a function of lead time $T_{o}^{k}(\tau)$ is generally used in the last term of the right-hand side of Eq. (1) instead of $T_{a}^{k}(\tau)$. However, there are few observed precipitation datasets covering the entire globe before 1979 owing to the lack of satellite data. When we focus on SST and ocean subsurface temperature fields, the model drift estimated from the observational anomaly is almost the same as that in Eq. (1) in our system. Moreover, the model drift estimated in Eq. (1) is negligible in the LOW and HI models as described below. Therefore, the definition of model drift does not affect the results of our analysis.

Figures 2 and 3 show the model climate drift during the prediction estimated in Eq. (1). During the one-year lead time, an SST model drift of less than $-0.3 \mathrm{~K}$ appears near the east coast of Japan in the MID model (Fig. 2b). A model drift with a similar pattern also emerges for a vertically averaged temperature from the surface to $300 \mathrm{~m}$ (VAT300) in the MID model but is not as apparent in the LOW and $\mathrm{HI}$ models (Figs. 3a-c). In the following threeyear lead time, the SST drift in the MID model is more than $1.0 \mathrm{~K}$ in the equatorial Pacific and less than $-1.0 \mathrm{~K}$ in the Kuroshio-Oyashio extension region (Fig. 2e), which resembles the typical SST

\section{SST: Systematic error during predictions}
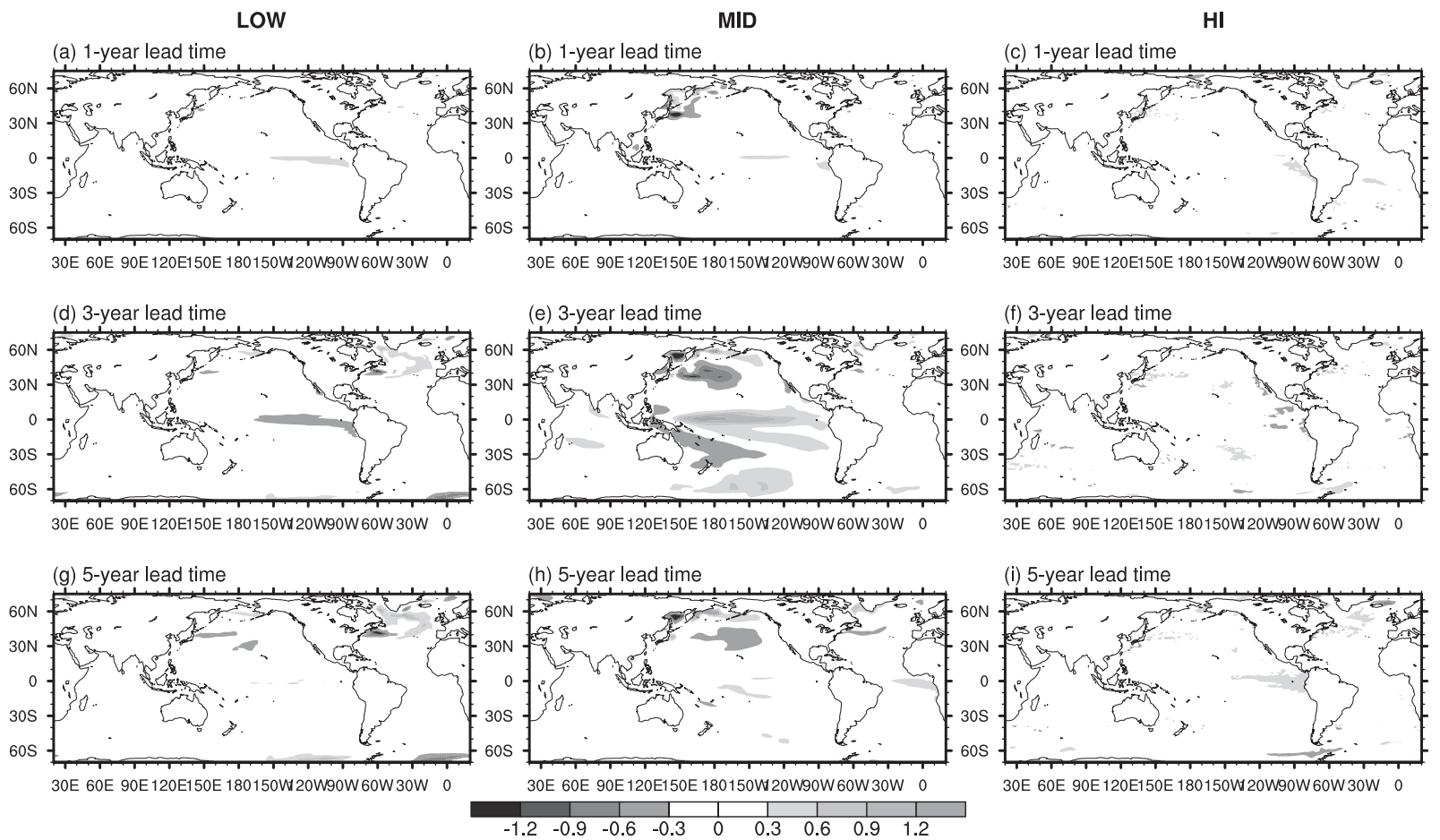

Fig. 2. Yearly SST systematic errors during prediction estimated by equation (1) in the LOW (left), MID (center), and HI models (right). Upper, middle, and lower panels show the systematic error at one-, three-, and five-year lead times, respectively. Light and dark shading indicate positive and negative systematic errors, respectively, with $0.2 \mathrm{~K}$ intervals. 
VAT300: Systematic error during predictions
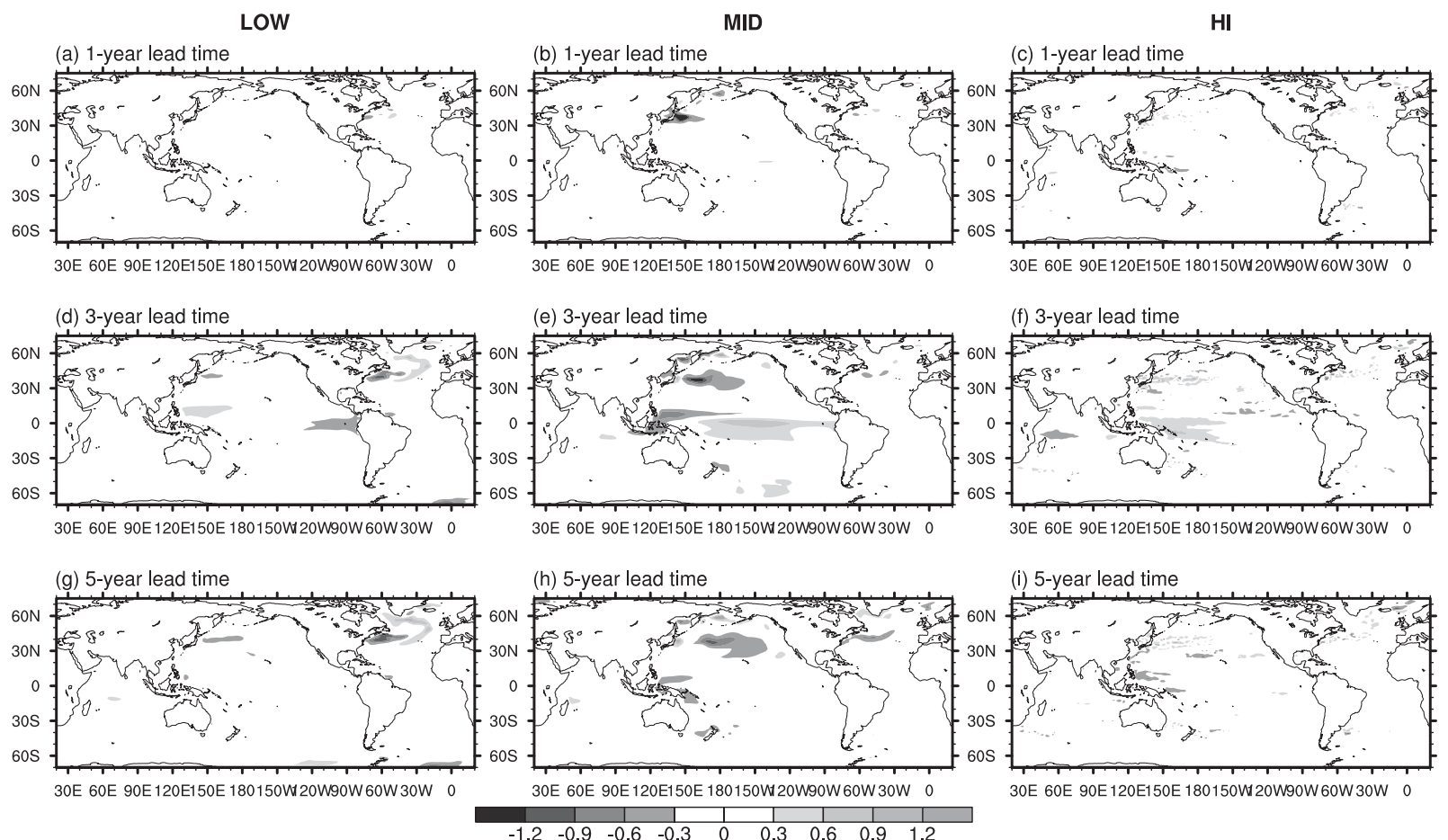

Fig. 3. Same as Fig. 2, but for ocean heat content vertically integrated from the surface to $300 \mathrm{~m}$ (VAT300).

pattern associated with El Niño-Southern Oscillation (ENSO) events (Watanabe et al. 2010). Consistent with the ENSO-like SST drift pattern, the VAT300 drift in the MID model shows an eastwest gradient in the tropical Pacific (Fig. 3e). On the other hand in the LOW and HI models, the SST and VAT300 model drifts remain small in the Pacific during this period, except for a La Niñalike SST drift due to the lower predictability of the 1997/98 El Niño event (Figs. 2d, 2f, 3d, and 3f). After the five-year lead time, the drift in the MID model decreases in amplitude in the tropical Pacific, whereas the negative drift in SST and VAT300 is still prominent in the North Pacific (Figs. $2 \mathrm{~h}$ and 3h). The SST and VAT300 model drifts in the LOW model appear during the three- and five-year lead times in the North Atlantic (Figs. 2d, 2g, 3d and $3 \mathrm{~g}$ ), which is not our target in the present study.

In summary, the model drift during prediction in the Pacific is relatively large in the MID model but negligible in the LOW and HI models. Therefore, we apply a post-processing of forecasts to remove the model drift estimated in Eq. (1), for the MID model but not for the LOW and HI models. Nevertheless, our HCST experiment shows consistent results among all models as shown in the next section. In the MID model, the reason for the smaller systematic errors at the three-year lead time compared with the five-year lead time is still unknown. To improve the model and its climate predictive skill, the dynamical process that induces model drift during prediction is an important topic for future studies.

\section{Predictability of Pacific climate change}

To examine decadal predictability in our hindcast experiments, we measured the three-year-mean SST predictive skill by examining the anomaly correlation coefficient $(\mathrm{ACC})$ between the assimilation and the ensemble mean prediction (Fig. 4). All the models have three predictable regions: the Indian Ocean, the tropics to the North Atlantic, and the western subtropical Pacific. In our HCST experiments, SST anomalies have high predictive skill in the Indian Ocean during the 10-year prediction but lose their skill in the equatorial Pacific for the initial three years. Chikamoto et al. (2011) suggested that 
SST: ACC
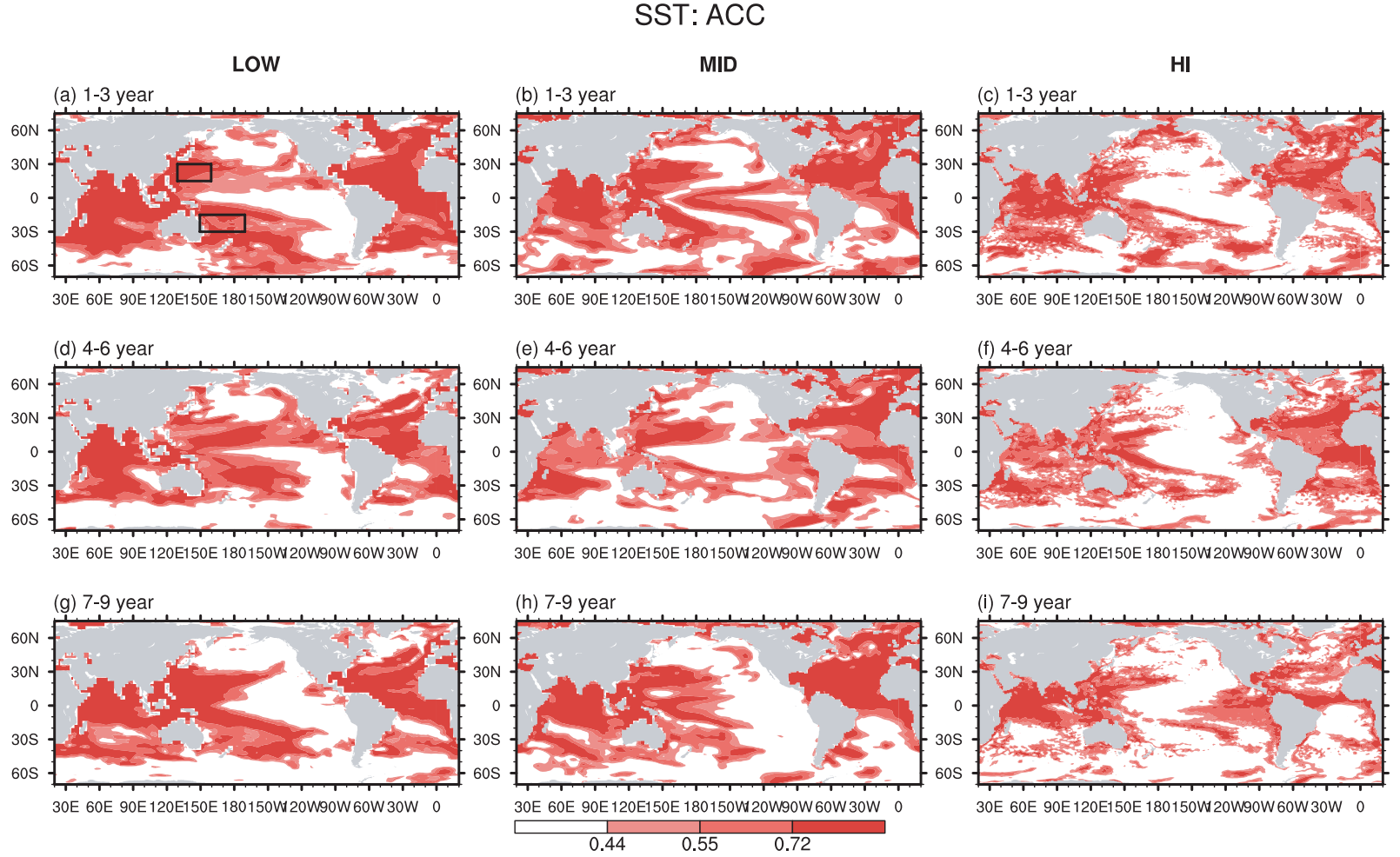

Fig. 4. Three-year-mean SST predictability in the LOW (left), MID (center), and HI models (right). The predictive skill is measured according to the ACC between the ASSM and HCST experiments in each model. Correlation coefficients of $0.44,0.55$, and 0.72 correspond to the statistical significance at the $90 \%, 95 \%$, and $99 \%$ levels, respectively, using a one-sided Student t-test with eight degrees of freedom. Black boxes in Fig. $4 \mathrm{a}$ indicate regions in the northern and southern subtropical Pacific.

the externally forced component is dominant in the Indian Ocean, whereas SST anomalies in the equatorial Pacific are less predictive on longer timescales owing to strong SST damping by climatological upwelling. In the Atlantic Ocean, previous studies have obtained predictable signals for internal variability related to the Atlantic meridional overturning circulation (Keenlyside et al. 2008) and the meridional gradient mode in the tropics (Chikamoto et al. 2011), as well as the externally forced component. Higher predictive skills for SST also appear in the western subtropical Pacific, which should be distinguished from the interannual ENSO variability in terms of timescale.

Figures 5 and 6 show the SST time series averaged in the western region of the subtropical Pacific for the observations (black solid line), assimilation (gray), externally forced component (red), and prediction (blue). In the northern subtropical Pacific, observed SST anomalies vary within $\pm 0.2 \mathrm{~K}$ before 1995. From 1995 to 2000, SST anomalies suddenly increase up to $0.6 \mathrm{~K}$. This rapid warming from 1995 to 2000 is also observed in the southern subtropical Pacific. The timing of this climate change is consistent with the recent shifts in the typhoon frequency in Taiwan ( $\mathrm{Tu}$ et al. 2009), the East Asian summer monsoon (Kim et al. 2011), the surface air temperature in the Tibetan Plateau $(\mathrm{Xu}$ et al. 2009), the subsurface temperature in the Kuroshio-Oyashio extension region (Minobe 2002), and the coastal Oyashio (Yasuda 2003; Tatebe and Yasuda 2005), as described in the Introduction. Since the SST rapid warming is prominent in the western subtropical Pacific where SST has higher predictive skills, we then focus on this stepwise warming during the late 1990s.

The sudden SST warming in the late 1990s appears in the NoAS experiment (red lines in Figs. 5 and 6). Although the externally forced components estimated by ensemble mean of three members in the MID and HI models may include relatively large internal variability owing to the limited num- 
Northern Subtropical Pacific

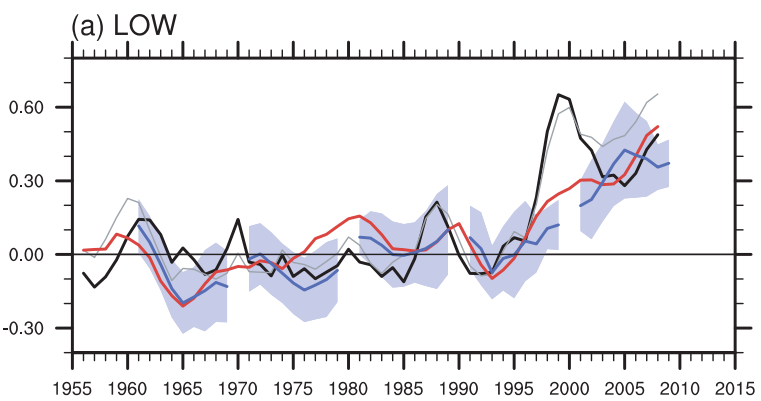

(c) MID

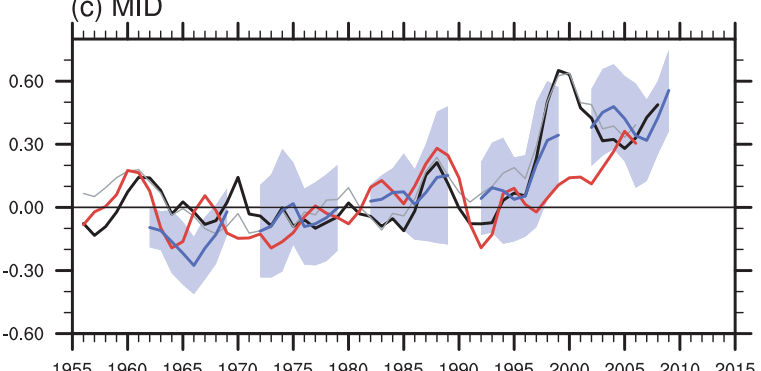

(e) $\mathrm{HI}$

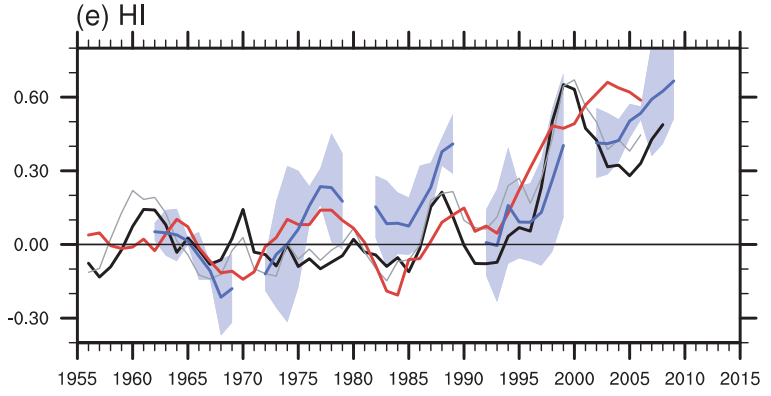

Southern Subtropical Pacific

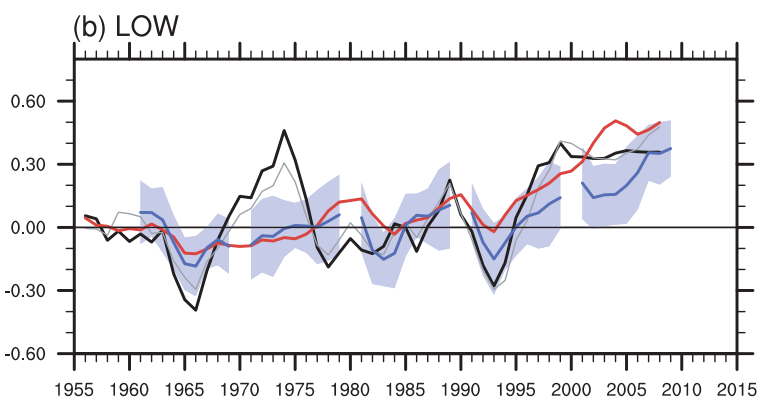

(d) MID
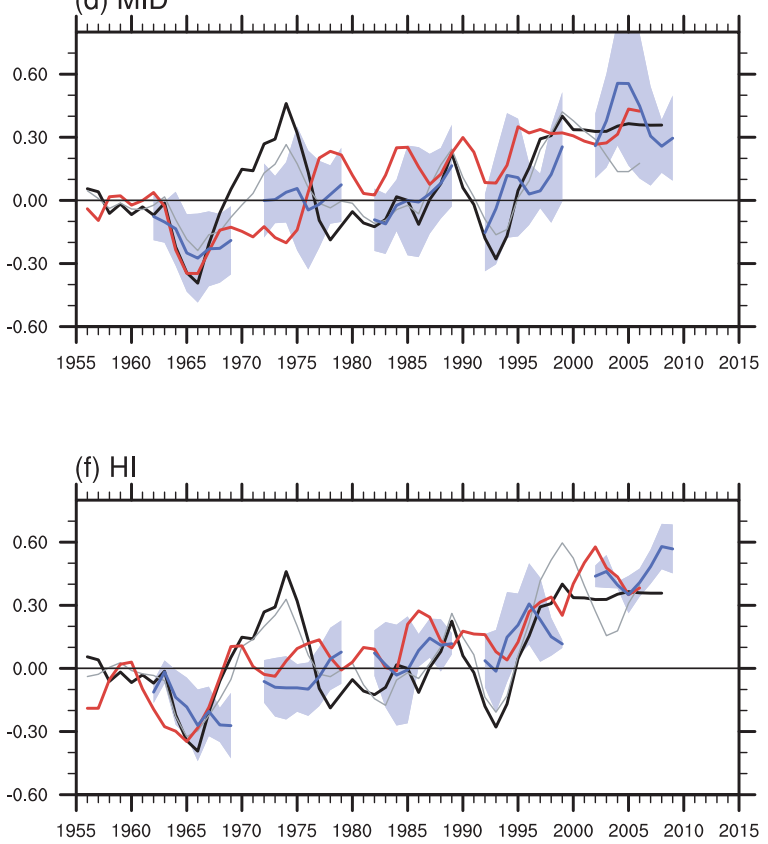

Fig. 5. Time series of SST anomaly averaged in the western region of the northern $\left(130^{\circ} \mathrm{E}-160^{\circ} \mathrm{E}, 15^{\circ} \mathrm{N}-\right.$ $30^{\circ} \mathrm{N}$; left panels) and southern subtropical Pacific $\left(150^{\circ} \mathrm{E}-170^{\circ} \mathrm{W}, 30^{\circ} \mathrm{S}-15^{\circ} \mathrm{S}\right.$; right panels $)$. These regions are indicated by the black boxes in Fig. 4a. Black, gray, and red lines represent the observations, the ASSM run, and the NoAS run with three-year-mean running filtering, respectively. Blue lines and shading show the ensemble mean prediction and its spread started in 1960/61, 1970/71, 1980/81, 1990/91, and 2000/01 in the $(\mathrm{a}, \mathrm{b}) \mathrm{LOW},(\mathrm{c}, \mathrm{d}) \mathrm{MID}$, and $(\mathrm{e}, \mathrm{f}) \mathrm{HI}$ models.

ber of ensemble members (Table 3), the NoAS experiments in all models have the same warming trends during the late 1990s in both hemispheres of the subtropical Pacific. These warming trends are also captured by the predictions started in 1995/96 in all models (blue lines in Fig. 6), and the magnitude of the warming in the HCST experiment is almost comparable to that in the NoAS experiment. As described below, however, a spatial structure of the SST warming in the HCST experiment is differ- ent from the NoAS experiment, which contributes to induce an atmospheric response to SST such as precipitation pattern. The influence of internally generated and externally forced variations on the stepwise shift is discussed in the next section.

To examine the pattern associated with the climate change in the late 1990s, we estimate the fiveyear-mean difference between the 1991-1995 and 2000-2004 periods. Figure 7 shows the climate change patterns during the late 1990s in the obser- 
Northern Subtropical Pacific

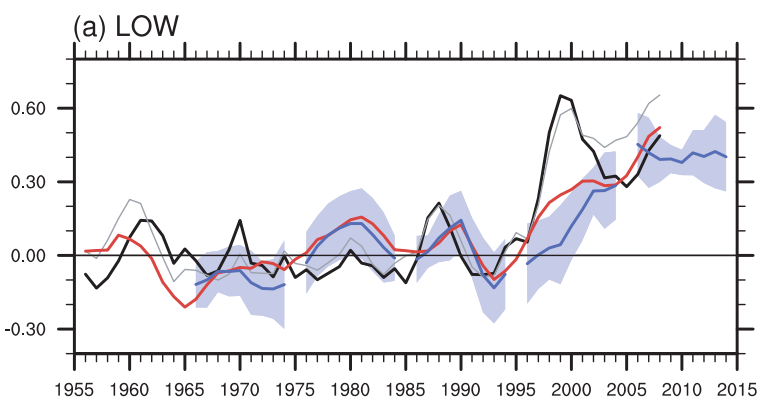

(c) MID

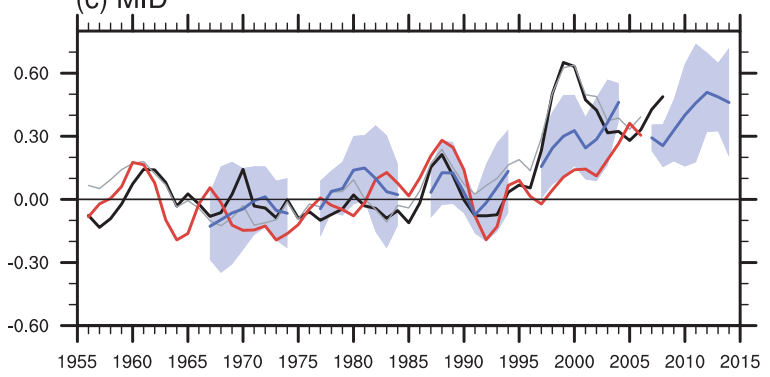

(e) $\mathrm{HI}$

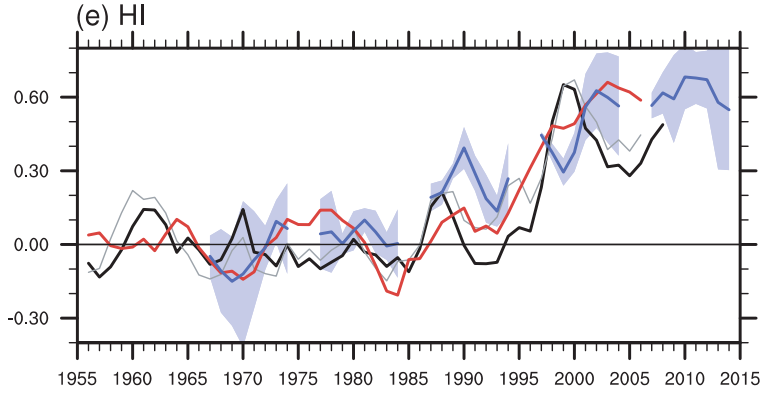

Southern Subtropical Pacific

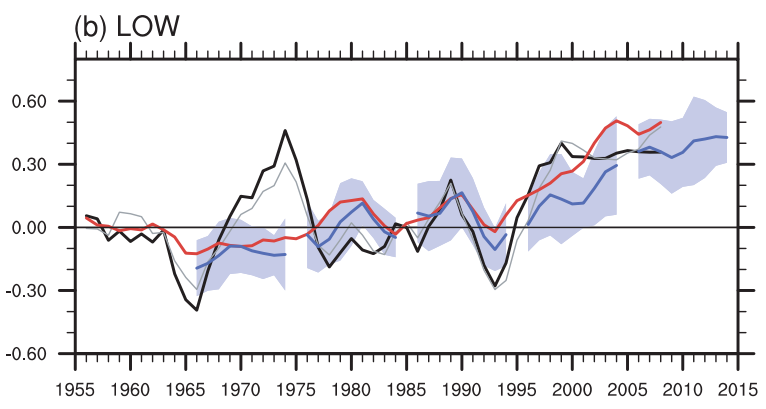

(d) MID
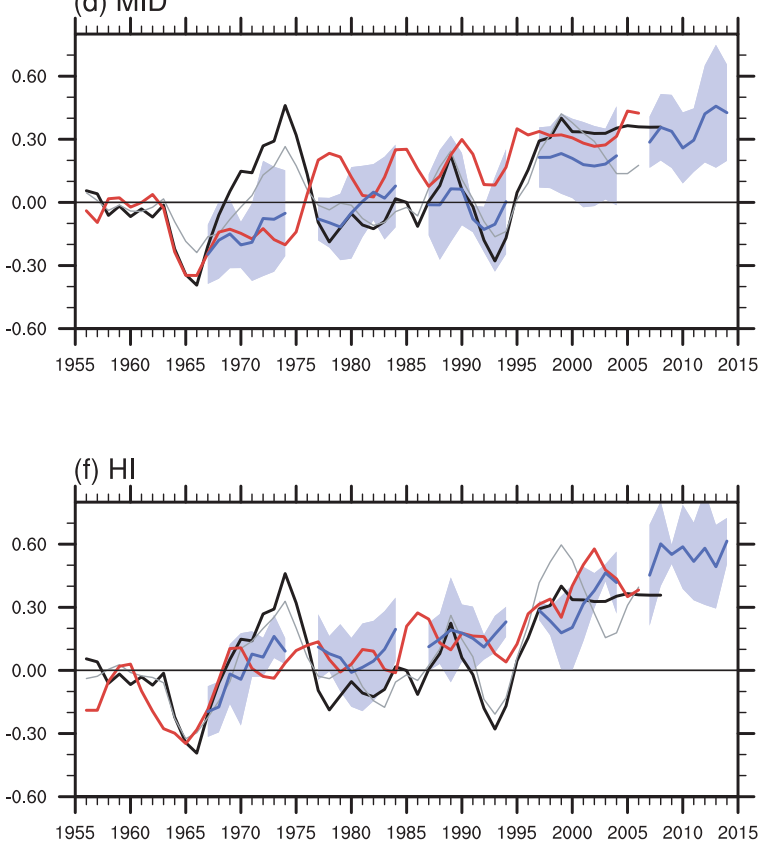

Fig. 6. Same as Fig. 5, but for predictions started in 1965/66, 1975/76, 1985/86, 1995/96, and 2005/06.

vations and the ASSM experiment. During the late 1990s, the observation shows SST cooling in the central tropical Pacific, a horseshoe-shaped pattern of SST warming in the western subtropical Pacific (Fig. 7b), and an east-west gradient of VAT300 in the tropical Pacific (Fig. 7c). SST and VAT300 cooling is also observed around $45^{\circ} \mathrm{N}$ extending from the west coast of North America (Figs. 7b and 7c). In the North Pacific, the PDO-like SST and VAT300 changes are consistent with a previous study (Minobe 2002). Because the observed ocean temperature anomalies are assimilated into MIROC, these observed patterns of SST and VAT300 are well represented in the ASSM experiments.
Associated with the horseshoe-shaped pattern in the tropical Pacific SST, the observed precipitation change has a horseshoe shape in the tropical Pacific (Fig. 7a). This horseshoe shape is simulated by all models (Figs. 7a, 7d, 7g, and 7j). In addition, an observed SLP increase near the center of $\left(30^{\circ} \mathrm{N}\right.$, $\left.150^{\circ} \mathrm{W}\right)$ and $\left(40^{\circ} \mathrm{S}, 140^{\circ} \mathrm{W}\right)$ emerges in all models with slightly different features because of model deficiencies. Moreover, an observed SLP decrease in the Bering Sea region (near the center of $60^{\circ} \mathrm{N}$, $180^{\circ}$ ) is simulated by the HI model (Figs. 7a and $7 \mathrm{j}$ ). In our ASSM experiment, the agreement between the simulated atmospheric changes and the observations suggests that these atmospheric changes are induced by the SST changes and/or 


\section{Climate change from 1991/95 to 2000/04 (ASSM)}
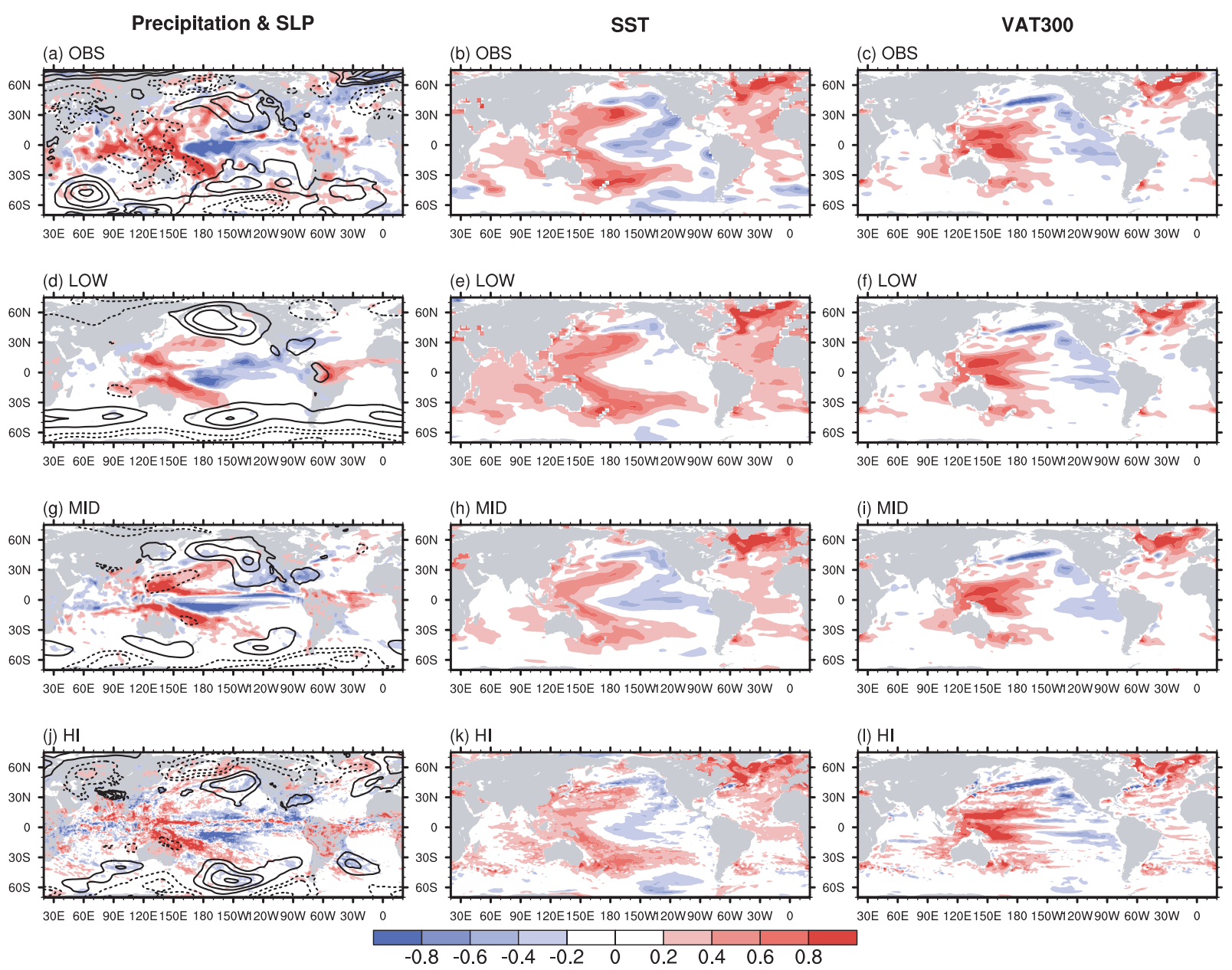

Fig. 7. Difference maps between the 1991-1995 and 2000-2004 means in (a,b,c) the observations and (d,e,f) the LOW, $(\mathrm{g}, \mathrm{h}, \mathrm{i}) \mathrm{MID}$, and $(\mathrm{j}, \mathrm{k}, \mathrm{l})$ HI models in the ASSM experiments. Shading in the left, middle, and right panels indicates precipitation $\left(0.2 \mathrm{~mm}^{-1 a y}{ }^{-1}\right.$ intervals), SST $(0.2 \mathrm{~K})$, and VAT300 $(0.2 \mathrm{~K})$, respectively. Contours in left panels are SLP (contour intervals are $0.5 \mathrm{hPa}$; negative values are dashed), and the zero contour is omitted. Observational datasets of precipitation, SLP, and ocean temperature are those used in GPCP, ERA-I, and the monthly objective analysis of Ishii and Kimoto (2009).

the externally forced component because no atmospheric data are assimilated into MIROC. In other words, these atmospheric changes would be potentially predictable if a successful prediction of the SST changes during the late 1990s is achieved by the HCST experiment.

Figure 8 shows the climate shift pattern simulated by the NoAS experiment. In the LOW model, the SST warming has a zonally uniform structure, whereas the changes in precipitation, SLP, and VAT300 are unclear (Figs. 8a-c). This SST warming pattern is not consistent with the observations and assimilation (Figs. 7 and 8). In the NoAS experiment, prominent changes in SST and precipitation appear in the MID and HI models, but their patterns are quite different in these models. The SST warming in the equatorial Pacific is exaggerated in the MID model but not as large in the HI model (Figs. 8e and 8h). In contrast, the SST warming around $30^{\circ} \mathrm{N}$ is large in the HI model but small in the MID model. In the eastern part of Australia, precipitation decreases in the MID model but increases in the HI model (Figs. 8d and $8 \mathrm{~g})$. These inconsistencies may be the reason that 


\section{Climate change from $1991 / 95$ to $2000 / 04$ (NoAS)}
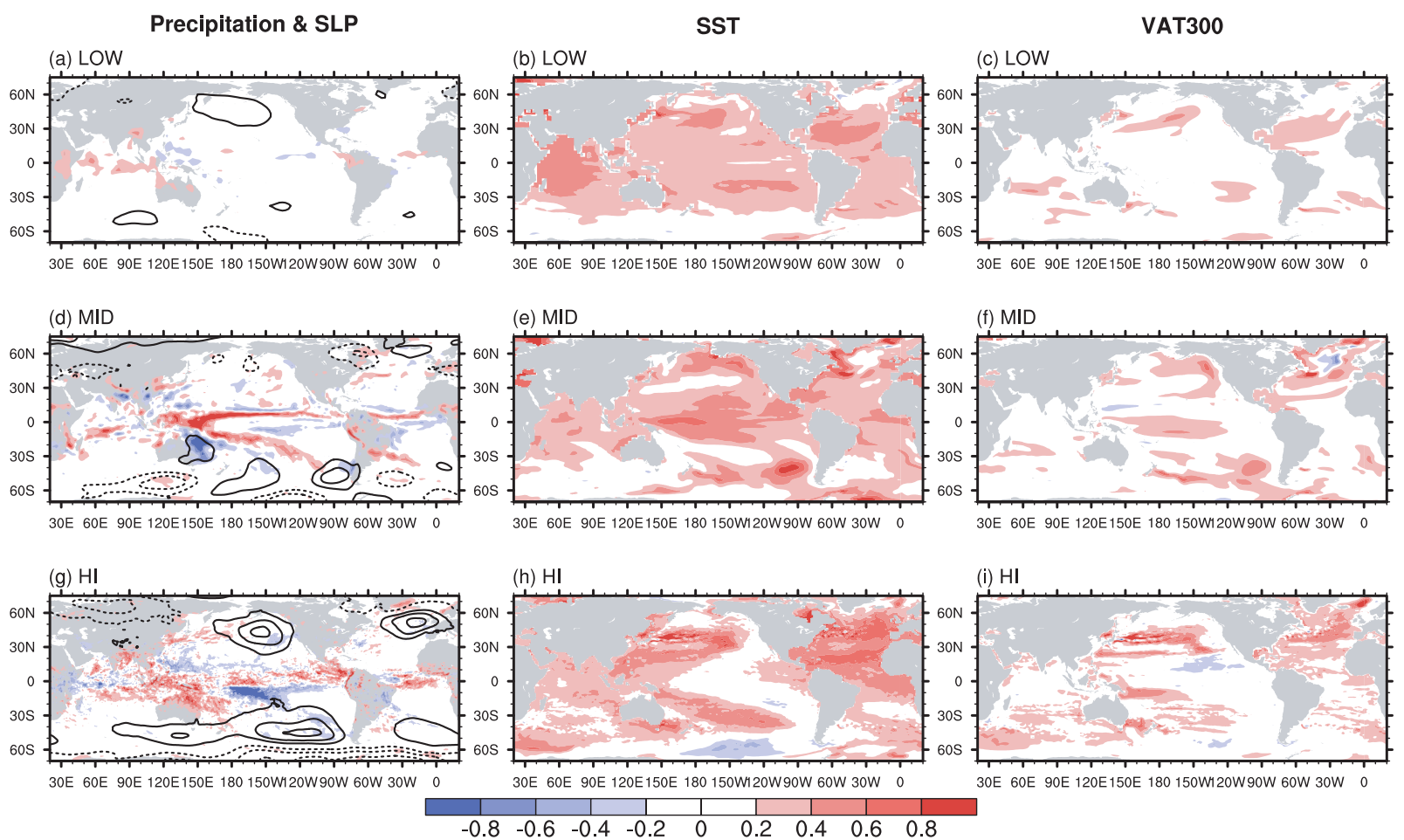

Fig. 8. Same as Fig. 7, but for the LOW, MID, and HI models in the NoAS experiment.

the internal variability in the NoAS experiment is still large in the MID and HI models as discussed in the next section. The internal variability in the NoAS experiment would be reduced by increasing the number of ensemble members or by considering the inter-model mean.

Although the observed shifted patterns in SST, precipitation, and SLP seem to be similar to that in the HI model's NoAS experiment, our HCST experiments that started in 1995 or 1996 show more realistic patterns in all models (Fig. 9). The horseshoe-shaped pattern of SST warming on the western side of the Pacific and the relative cooling in the equatorial Pacific is simulated well in the HCST experiment (Figs. 9b, 9e, and 9h). In addition, the tropical Pacific's east-west gradient in precipitation and VAT300 is also captured in all models in the HCST experiment. Although the HI model shows similar shift patterns in SST, precipitation, and SLP in the NoAS and HCST experiments (Figs. $8 \mathrm{~g}-\mathrm{h}$ and $9 \mathrm{~g}-\mathrm{h}$ ), the observed cooling of VAT300 around $40^{\circ} \mathrm{N}$ in the North Pacific (Figs. 7c and 7l) is simulated by HCST but not the NoAS experiments (Figs. 8i and 9i). The subsurface tem- perature signals simulated by the HCST experiments suggest a contribution from internal variability to the climate shift during the late 1990s, as discussed in the next section.

Atmospheric changes associated with the climate shift during the late 1990s seem to become more realistic when the horizontal resolution is increased. When we focus on the large-scale structure, the observed pattern of precipitation is simulated well by the ASSM and HCST experiments in all models: An enhanced precipitation trend in the western tropical regions of the Pacific and Atlantic and a suppressed precipitation trend in the central to eastern equatorial Pacific (left panels in Figs. 7 and 9). However, the observed enhanced precipitation trends in the Indian Ocean, the North Pacific, and the narrow zone of the off-equatorial Pacific near $5^{\circ} \mathrm{N}$ are not captured by the LOW model. In contrast, these precipitation trends become clearer and sharper in the HI model (Figs. $7 \mathrm{j}$ and $9 \mathrm{~g}$ ). The observed decreasing trends in SLP around Russia, the Aleutian Islands, and the center of $\left(60^{\circ} \mathrm{S}, 135^{\circ} \mathrm{E}\right)$ also seem to be simulated by the HI model in both the ASSM and HCST experiments; however, these 


\section{Climate change from 1991/95 to 2000/04 (HCST)}
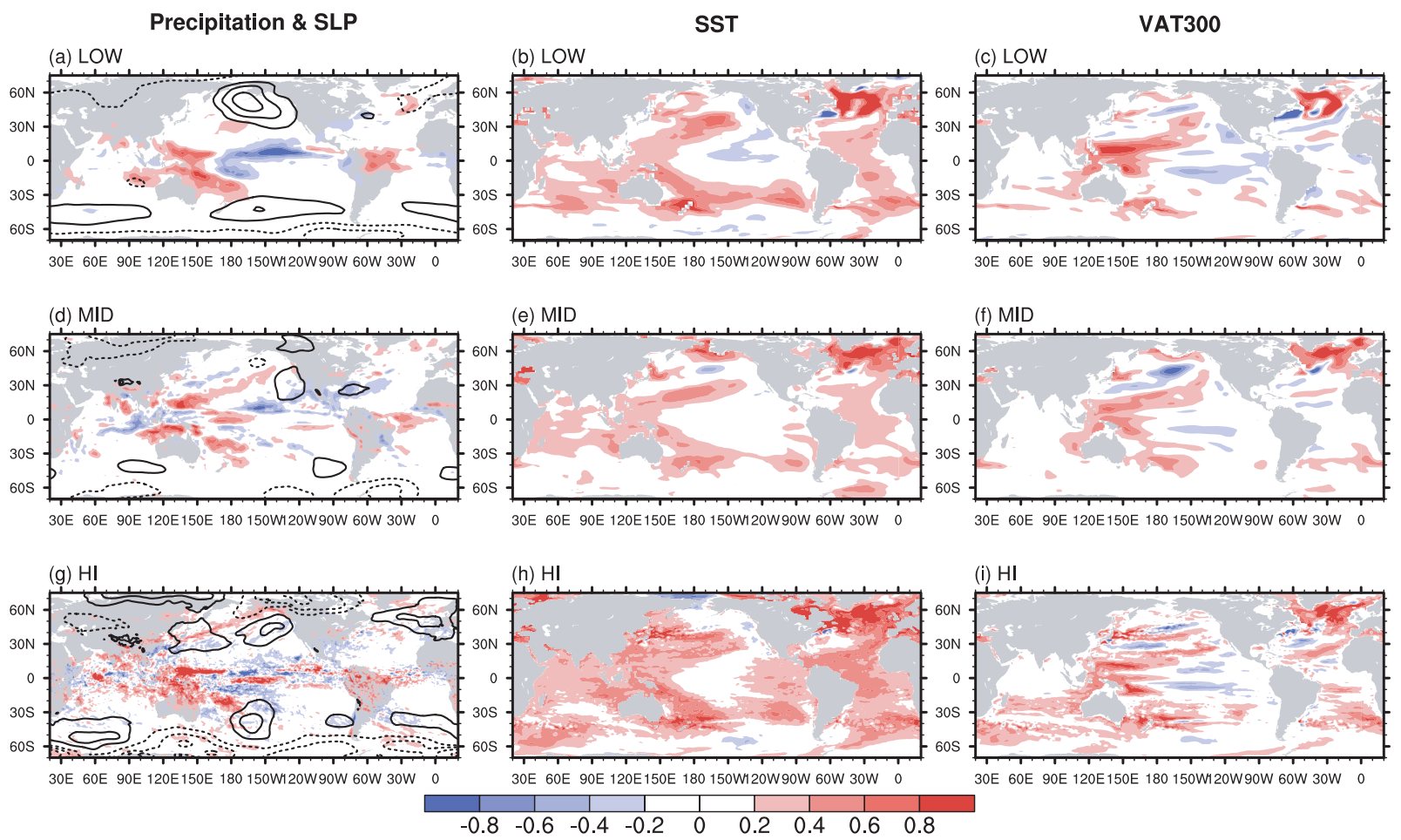

Fig. 9. Same as Fig. 7, but for the LOW, MID, and HI models in the HCST experiment. Predicted climate change is obtained from the difference between the 1991-95 means in the ASSM experiment and the 200004 means in the predictions started in 1995 or 1996.

centers of action are slightly shifted in the HI model.

To examine the time evolutions of the stepwise SST warming during the late 1990s, we estimate the three-year-averaged SST and SLP anomalies from the 1991-1995 mean in the observations and the LOW model (Fig. 10). Here, we show only the results of the LOW model because it has the largest number of ensemble members in the HCST and NoAS experiments. However, consistent results in the HCST experiment are also obtained in the MID and HI models. During 1996-1998, the observed SST anomalies are positive in the western and eastern tropical Pacific and negative in the central tropical Pacific and Kuroshio-Oyashio extension region (Fig. 10a). This SST warming in the western tropical Pacific and cooling in the central and North Pacific become prominent during 19982000 (Fig. 10d) and persist in the following 20002002 period (Fig. 10g). Associated with these SST warming and cooling patterns, the observed SLP anomalies become negative in the western tropical
Pacific and positive in the midlatitude regions of the North and South Pacific during 1998-2000 and 2000-2002. In the HCST experiment, the welldeveloped negative SST anomalies in the central tropical Pacific emerge during 1996-1998 (Fig. 10b), two years earlier than observed. Although the negative SST anomalies in the central tropical Pacific decay in the following 1998-2000 and 2000-2002 periods, positive SST anomalies in the western tropical Pacific and positive SLP anomalies in the Pacific mid-latitude region in both hemispheres are well developed during 2000-2002 (Figs. 10e and 10h). The observed negative SST anomalies at $45^{\circ} \mathrm{N}$ also appear in the HCST experiment, with a smaller amplitude than the observation. In contrast, in the NoAS experiment, the SST anomalies gradually increase with an almost zonally uniform pattern from 1996-1998 to 2000 2002 (Figs. 10c, 10f, and 10i). This monotonic increase in the NoAS experiment also includes the recovery from the global cooling event caused by the Mount Pinatubo eruption in 1991. In the next sec- 


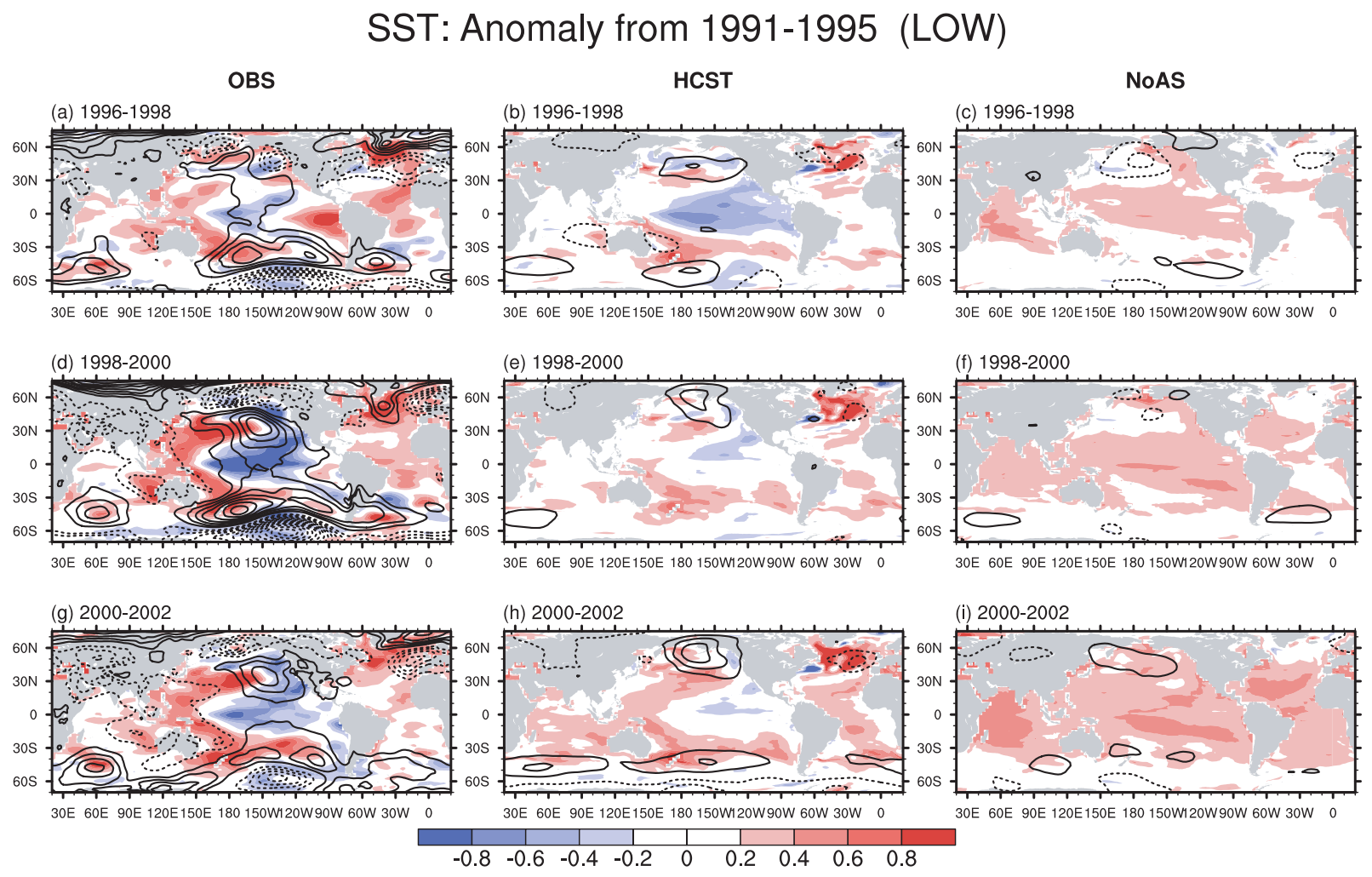

Fig. 10. Three-year mean deviation of SLP and SST from the 1991-1995 mean in the observations and the LOW model. Left, center, and right panels are the observations and the HCST and NoAS experiments, respectively. Upper, middle, and lower panels are the 1996-1998, 1998-2000, and 2000-2002 means, respectively. Shading indicates SST deviations of $0.2 \mathrm{~K}$. Contours represent SLP deviations $(0.5 \mathrm{hPa}$ interval). Negative contours are dashed; zero contours are omitted.

tion, we discuss the influence of internally generated and externally forced variations on the stepwise shift during the late 1990s.

\section{Internally generated and externally forced variations}

As shown in Figs. 5 and 6, the magnitude of SST warming in the northern and southern subtropical Pacific during the late 1990s is almost the same in the NoAS and HCST experiments. However, the observed climate shift pattern in the atmospheric and oceanic variables is consistent with the HCST experiment for all three MIROC resolutions but not with the NoAS experiment. In this section, we discuss the predictable component of the climate shift during the late 1990s in the NoAS and HCST experiments.

In our NoAS and HCST experiments, the externally forced component includes natural and anthropogenic forcing such as greenhouse gas and aerosol concentrations, solar cycle variations, and major volcanic eruptions. In particular, the stepwise shift during the late 1990s is affected by the natural forcing factor of major volcanic activity, i.e., the Mount Pinatubo eruption. Following this eruption in 1991, the surface air temperature exhibited global cooling for a few years and then showed an upward trend (Soden et al. 2002; Gleckler et al. 2006). Although major volcanic eruptions can reduce the predictability of internally generated variability (Robock 2000; Yokohata et al. 2005), this effect of the Pinatubo eruption is irrelevant to the predictions started in 1995 or 1996 in our HCST experiments. Shiogama et al. (2010) suggested that the cooling effect caused by the Pinatubo eruption penetrated into the upper ocean to a depth of about $100 \mathrm{~m}$ during the initial five years after the volcanic eruption. Because our analyses are based on the difference from the 1991-1995 mean, our results include the recovery from the 


\section{VAT300 \& surface wind: Anomaly from 1991-1995 (LOW) OBS}
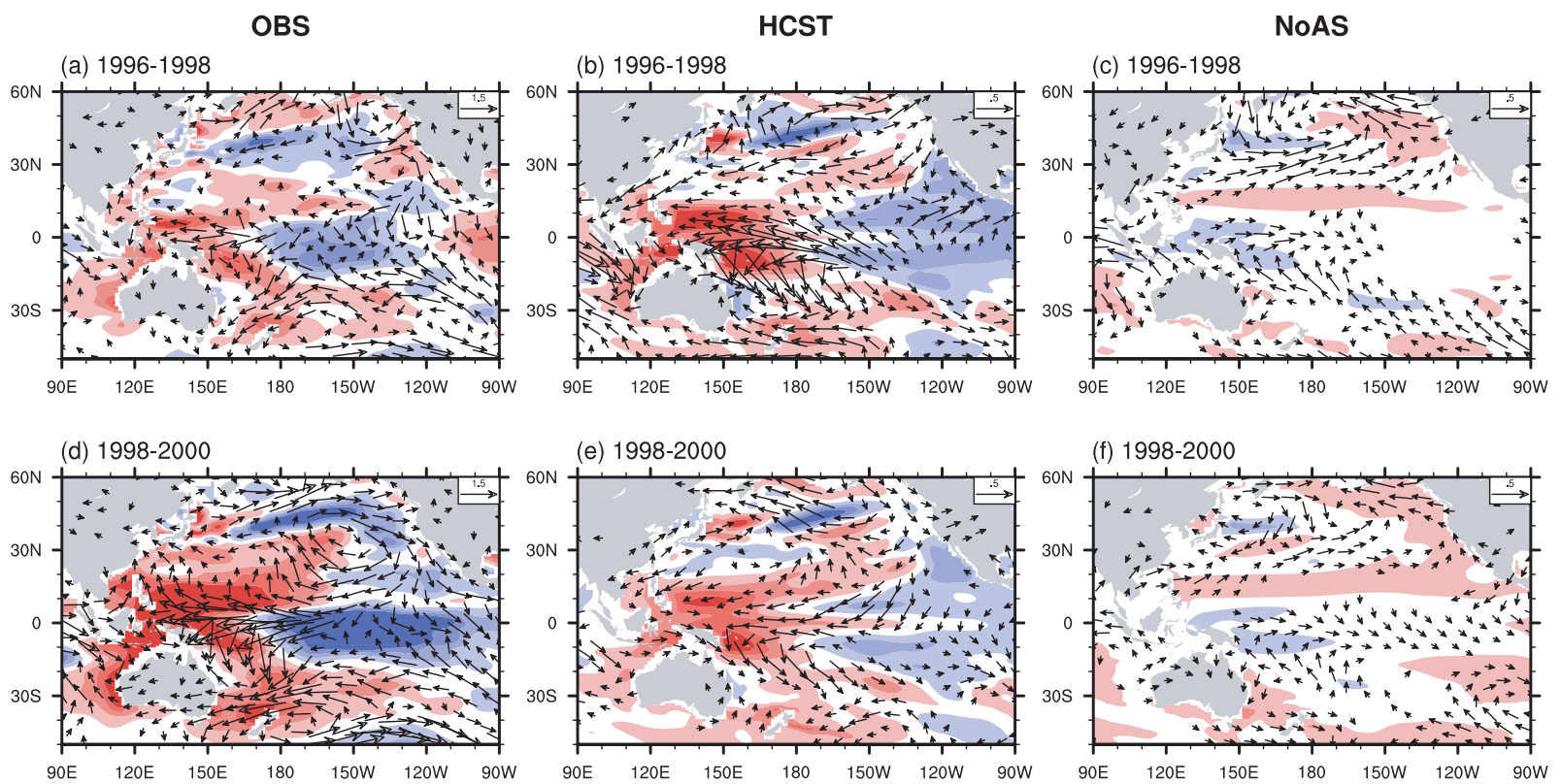

(g) 2000-2002

(h) $2000-2002$

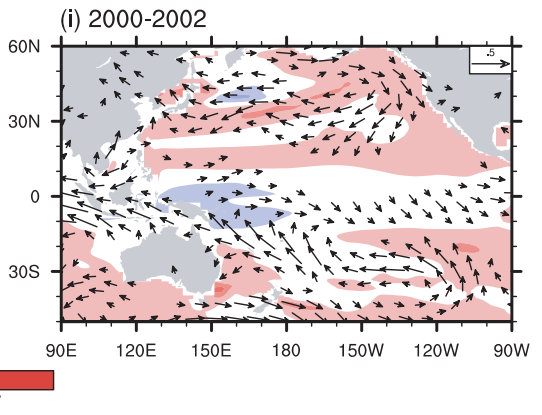

$\begin{array}{llllllll}-0.7 & -0.5 & -0.3 & -0.1 & 0.1 & 0.3 & 0.5 & 0.7\end{array}$

Fig. 11. Same as Fig. 10, but for VAT300 (shaded) and surface wind at $10 \mathrm{~m}$ (vector: $\mathrm{m} \mathrm{s}^{-1}$ ) in the Pacific.

cooling effect of the Mount Pinatubo eruption. The recovery from the cooling induced by the eruption is naturally involved in the stepwise changes, particularly, those in the atmospheric and ocean surface variables during the late 1990s, which may make it difficult to evaluate the predictable component induced by internal variability.

When we focus on the subsurface ocean temperature, for example, VAT300, the signals of internally generated variability become clearer than those of externally forced variation. Figure 11 shows the time evolutions of VAT300 and surface wind anomalies from the 1991-1995 mean in the observations, and the HCST and NoAS experiments in the LOW model. During 1996-1998, the observations show an east-west gradient of VAT300 anomalies in the tropical Pacific associated with an anomalous easterly wind in the equatorial Pacific (Fig. 11a). The east-west gradient of VAT300 anomalies in the tropics becomes prominent and extends poleward in the following 1998-2000 and 2000-2002 periods (Figs. 11d and 11g). In particular, the positive VAT300 anomalies in the western tropical Pacific, extending northeastward to the center of the positive SLP anomalies, accompany clockwise wind circulation during these periods. This clockwise circulation can increase the subsurface temperature owing to ocean dynamics forced by Ekman pumping, which in turn affects the atmospheric circulation through the SST changes in the tropical Pacific (Ose et al. 1997; Lau and Nath 2009). These changes imply that the atmosphere- 
ocean coupled process plays an important role in the stepwise shift during the late 1990s. These observed time evolutions of VAT300 and surface wind anomalies tend to be simulated by the HCST experiments, whereas the timing of the mature phase is earlier in the HCST experiment than in the observations (Figs. 11b, 11e, and 11h). In addition, the observed negative anomalies near $40^{\circ} \mathrm{N}$ from the 1996-1998 to 2000-2002 periods are also captured by the HCST experiment. However, in the NoAS experiment, there are no coherent anomalies

Table 4. Pattern correlation coefficients of the observed SST changes from 1991-1995 to 2000-2004 in the Pacific $\left(90^{\circ} \mathrm{E}-90^{\circ} \mathrm{W}, 70^{\circ} \mathrm{S}-70^{\circ} \mathrm{N}\right)$ with that in the HCST and NoAS experiments. All the SST difference maps in the observations and models were regridded to the LOW model grid.

\begin{tabular}{l|cr}
\hline & HCST & NoAS \\
\hline LOW & 0.81 & 0.20 \\
MID & 0.74 & 0.31 \\
HI & 0.66 & 0.55 \\
\hline
\end{tabular}

compared to the observations in the tropical and North Pacific during these periods (Figs. 11c, 11f, and 11i). Over the equatorial Pacific near the dateline, anomalous surface winds are westerly in the NoAS experiment but easterly in the observations and the HCST experiment. The anomalous westerly in the NoAS experiment implies the weakened Walker circulation, which is consistent with a climate model response to the external forcing (Vecchi et al. 2006; Timmermann et al. 2010).

Although the number of ensemble members is limited in the HCST and NoAS experiments, our results at all three MIROC resolutions show that oceanic initialization improves the predictive skill regarding the stepwise climate change during the late 1990s. Table 4 shows the pattern correlation coefficients of the observed SST change from the early 1990 s to early 2000 s with that in the HCST and NoAS experiments. At all MIROC resolutions, the pattern correlation coefficients in the HCST experiment are larger than those in the NoAS experiment. Figure 12 shows the ranges of the pattern correlation coefficients between the observations

\section{Pattern correlation}

(a) HCST

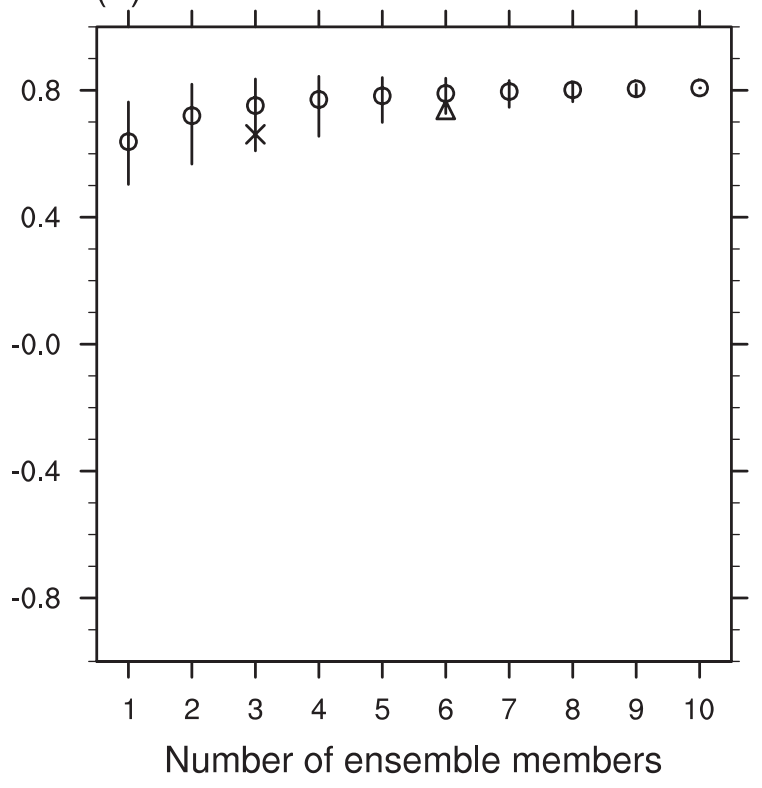

(b) NoAS

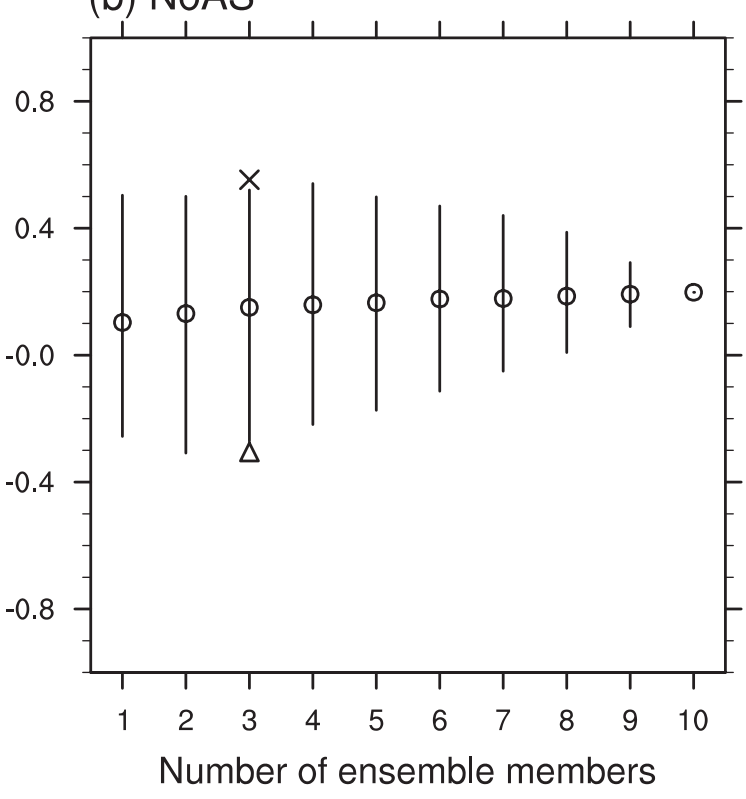

Fig. 12. Same as Table 4 but for pattern correlation coefficients associated with the ensemble-averaged number of members in the (a) HCST and (b) NoAS experiments. Circles and bars indicate the average and the range from maximum to minimum of pattern correlation coefficients in the LOW model, respectively, when random sampling was repeated 2000 times in 10 members. Triangles and crossmarks represent the MID and HI models, respectively. 
and the LOW model with respect to the number of ensemble members. In both the HCST and NoAS experiments, the ranges of the pattern correlation coefficients decrease with increasing number of ensemble members. When the number of ensemble members is small (for example, three), the range of the pattern correlation coefficients in the HCST experiment is much smaller than that in the NoAS experiment (about 0.3 in HCST and 0.8 in NoAS). This relatively small range in the HCST experiment suggests that oceanic initialization reduces the uncertainty in predicting the stepwise shift pattern during the late 1990s.

As shown in Fig. 8h and Table 4, the HI model with the three-member ensemble mean seems to simulate the observed SST shift pattern during the late 1990s. To evaluate whether the externally forced component is dominant in the HI model, we analyzed the signal-to-noise ratio of the yearly SST in the NoAS experiment (Fig. 13). In the Pacific Ocean, the signal-to-noise ratio is relatively large in the western tropical Pacific in the NoAS experiment in all models. In particular, the HI model shows a local maximum ratio of about 0.6 in the western tropical Pacific, whereas the ratio of the MID model is lower than 0.3 in that region. These results may indicate that the externally forced component is simulated well by the HI model. In the SST shift pattern during the late 1990s, the HI and MID models in the NoAS experiment are plotted around the maximum and minimum pattern correlation coefficients between the observations and around the three ensemble members of the LOW model, respectively (Fig. 12). However, it is noteworthy that the pattern correlation coefficients of the three ensemble members in the NoAS experiment have a large uncertainty in the LOW model (Fig. 12). In other words, internal variability such as a random large El Niño or La Niña could have affected the anomalous pattern in the NoAS experiment because of the small number of ensemble members. In addition to the uncertainty related to ensemble members, uncertainties due to the model deficiencies are also involved in the NoAS experiments. Therefore, care should be taken in evaluating the externally forced component in models with a small number of ensemble members such as the HI model. In any case, the predictability of the stepwise shift pattern during the late 1990s in the HI model, as well as in the LOW and MID models, is enhanced by initialization as shown in Table 4.

\section{Discussion and conclusions}

We have investigated the predictability of climate change in the Pacific on decadal timescales using low, medium, and high resolution versions of the coupled atmosphere-ocean model MIROC. In all models, our HCST experiments have exhibited predictive skills in the Indian Ocean, the tropics to the North Atlantic, and the western subtropical Pacific (Fig. 4). In the northern and southern subtropical Pacific, SST time series show rapid warming during the late 1990s (Figs. 5 and 6). This rapid SST warming is partly explained by the global warming signal estimated from the NoAS experiment. However, initialization contributes to the simulation of the observed shift patterns (Figs. 7, 8, and 9), indicating that the internal variability is also important for the climate shift during the late 1990s. In particular, the higher resolution model tends to simulate more detailed structures associated with the climate shift. Recent studies have reported rapid changes in the atmospheric and oceanic variables during the late 1990s (Minobe 2002; Yasuda 2003; Tatebe and Yasuda 2005; Tu et al. 2009; Kim et al. 2011; Hsu and Chen 2011). Our experiments would be helpful for understanding the physical processes involved in atmospheric and oceanic variability during the late 1990s.

The mechanism of the stepwise shift during the late 1990s is still controversial. Using the AGCM, $\mathrm{Tu}$ et al. (2009) suggested that the typhoon frequency shift near Taiwan is induced by the warm SST in the western and central equatorial Pacific. Hsu and Chen (2011) demonstrated that the enhanced precipitation in Eastern Australia, the Maritime Continent, Taiwan, and Korea are induced by the SST variability in the South Pacific, referred to as the 10-20-year South Pacific Decadal Oscillation. While these studies imply an atmospheric response to the SST variability, Minobe (2002) mentioned that the SLP increase over eastern North Pacific during the late 1990s is the main factor for inducing the ocean temperature changes in the North Pacific. In addition to these internally generated sources of atmosphere-ocean variability, the recent increase in surface air temperature over the Tibetan Plateau is associated with a black soot increase induced by anthropogenic forcing ( $\mathrm{Xu}$ et al. 2009). Our HCST and NoAS experiments suggest that the stepwise shift during the late 1990s is induced not only by internally generated atmospheric and oceanic variability but also by externally forced 


\section{Variance ratio of signal to total (NoAS)}

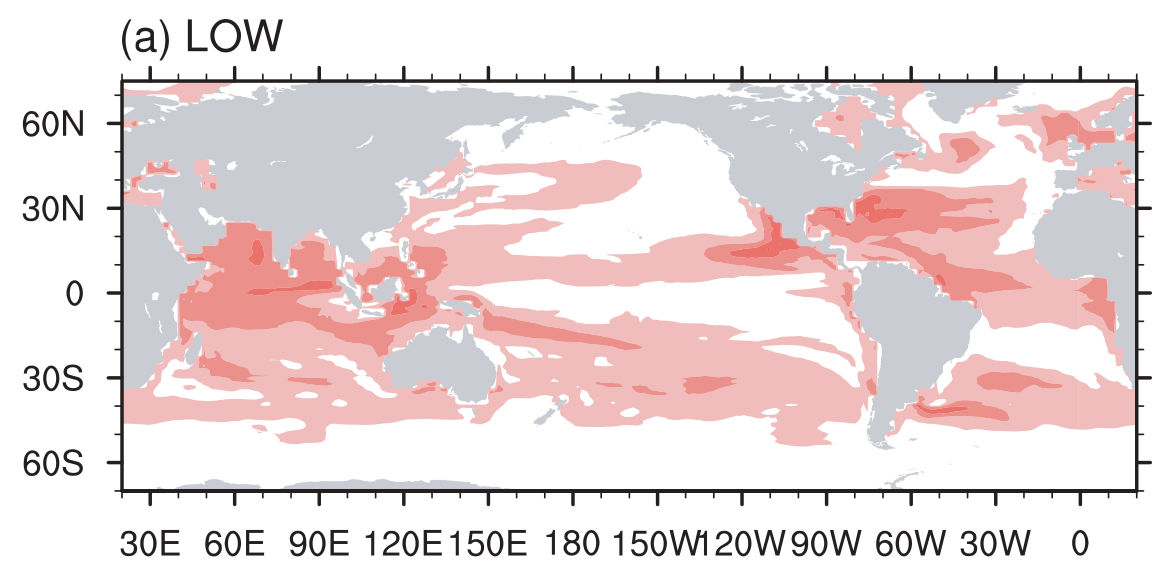

(b) MID

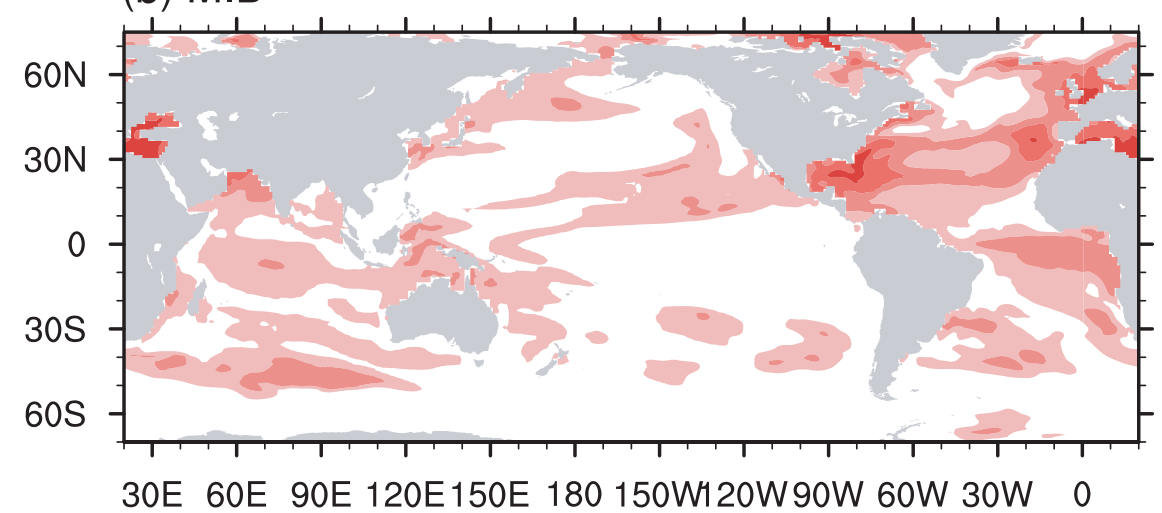

(c) $\mathrm{HI}$

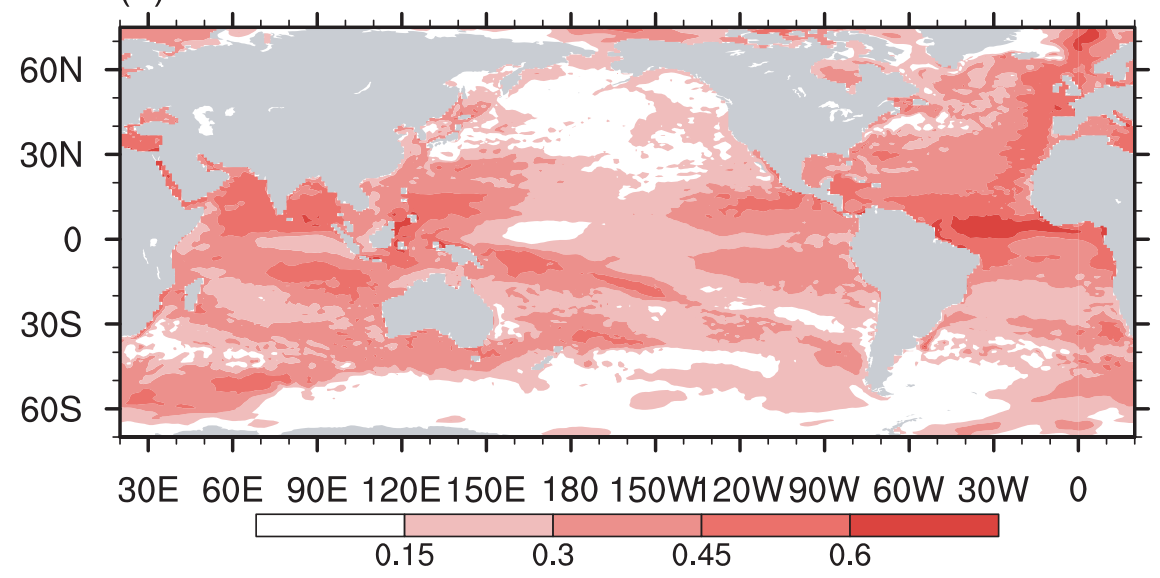

Fig. 13. Yearly SST variance ratio of externally forced signals to the total variability in the (a) LOW, (b) MID, and (c) HI models of the NoAS experiment. Variance ratio is estimated using the analysis of variance (ANOVA) technique (Rowell et al. 1995) for 1961-2005 with ten, three, and three ensemble members in the LOW, MID, and HI models, respectively. 
variation. Further studies to investigate the model response to external forcing and the initial memory involved in the atmosphere-ocean variability are needed to understand the mechanism of the stepwise shift during the late 1990s.

In IPCC's next report, AR5, hindcast and forecast experiments will be performed using many CMIP models with different types of initializations. Our HCST experiments in all models with slightly different initialization procedures show consistent predictive skills in the stepwise shift during the late 1990s, although the MID model has exhibited climate drift during prediction. This result suggests that the multi-model ensemble approach in CMIP5 is applicable to decadal climate prediction. In decadal climate prediction, many ensemble members are needed to evaluate the predictability associated with the internally generated and externally forced variations under limited computational resources. The multi-model ensemble of the CMIP5 models is a useful approach for overcoming the difficulty of decadal climate prediction.

\section{Acknowledgments}

The manuscript benefited from the constructive comments of three anonymous reviewers and Dr. Ose. This study was supported by the Japanese Ministry of Education, Culture, Sports, Science and Technology through the Innovative Program of Climate Change Projection for the 21st Century. The simulations were performed with the Earth Simulator at the Japan Agency for Marine-Earth Science and Technology and the NEC SX-8R at the National Institute for Environmental Studies.

\section{References}

Adler, R. F., G. Huffman, A. Chang, R. Ferraro, P. Xie, J. Janowiak, B. Rudolf, U. Schneider, S. Curtis, D. Bolvin, A. Gruber, J. Susskind, and P. Arkin, 2003: The version 2 global precipitation climatology project (GPCP) monthly precipitation analysis (1979-present). J. Hydrometeor., 4, $1147-$ 1167.

Berrisford, P., D. Dee, K. Fielding, M. Fuentes, P. Kallberg, S. Kobayashi, and S. Uppala, 2009: The ERA-Interim Archive. ERA report series, 1, 1-16.

Bloom, S. C., L. Takacs, A. M. da Silva, and D. Ledvina, 1996: Data assimilation using incremental analysis updates. Mon. Wea. Rev., 124, 1256-1271.

Chikamoto, Y., M. Kimoto, M. Watanabe, M. Ishii, T. Mochizuki, and S.-P. Xie, 2011: Multi-year predictability of the tropical climate under global warming. Geophys. Res. Lett., to be submitted.
Cox, P., and D. Stephenson, 2007: A changing climate for prediction. Science, 317, 207-208, doi:10.1126/ science. 1145956.

Gleckler, P. J., K. AchutaRao, J. M. Gregory, B. D. Santer, K. E. Taylor, and T. M. L. Wigley, 2006: Krakatoa lives: The effect of volcanic eruptions on ocean heat content and thermal expansion. Geophys. Res. Lett., 33, L17 702, doi:10.1029/ 2006 GL02677.

Hasumi, H., 2006: CCSR Ocean Component Model (COCO), Version 4.0. Center for Climate System Research Rep. 25, 103 pp, (Avaiable online at http://www.ccsr.u-tokyo.ac.jp/hasumi/COCO/ coco4.pdf.).

Hawkins, E., and R. Sutton, 2009: The potential to narrow uncertainty in regional climate predictions. Bull. Amer. Meteor. Soc., 90, 1095-1107.

Hibbard, K. A., G. A. Meehl, P. M. Cox, and P. Friedlingstein, 2007: A strategy for climate change stabilization experiments. $E O S, \mathbf{8 8}, 217-219$.

Hsu, H.-H., and Y.-L. Chen, 2011: Decadal to bi-decadal rainfall variation in the western Pacific: A footprint of South Pacific decadal variability? Geophys. Res. Lett., 38, L03 703, doi:10.1029/2010GL046278.

Huang, B., J. Kinter, and P. Schopf, 2002: Ocean data assimilation using intermittent analyses and continuous model error correction. Adv. Atmos. Sci., 19, 965-992.

INTERNATIONAL CLIVAR PROJECT OFFICE, 2011: Decadal and bias correction for decadal climate predictions. International CLIVAR Project Office, 150, CLIVAR Publication Series, (not peer reviewed).

Ishii, M., and M. Kimoto, 2009: Reevaluation of historical ocean heat content variations with timevarying XBT and MBT depth bias corrections. $J$. Oceanogr., 65, 287-299.

Ishii, M., M. Kimoto, K. Sakamoto, and S. Iwasaki, 2006: Steric sea level changes estimated from historical ocean subsurface temperature and salinity analyses. J. Oceanogr., 62, 155-170.

K-1 Model Developers, 2004: K-1 coupled GCM (MIROC) description, K-1 Tech. Rep., Vol. 1. Cent. for Clim. Syst. Res., Univ. of Tokyo, Tokyo, $34 \mathrm{pp}$.

Keenlyside, N. S., M. Latif, J. Jungclaus, L. Kornblueh, and E. Roeckner, 2008: Advancing decadal-scale climate prediction in the north Atlantic sector. $\mathrm{Na}$ ture, 453, 84-88, doi:10.1038/nature06921.

Kim, W.-M., J.-G. Jhun, K.-J. Ha, and M. Kimoto, 2011: Decadal changes in climatological intraseasonal fluctuation of subseasonal evolution of summer precipitation over the korean peninsula in mid-1990s. Adv. Atmos. Sci., 28, 591-600.

Lau, N., and M. Nath, 2009: A model investigation of the role of air-sea interaction in the climatological 
evolution and ENSO-related variability of the summer monsoon over the South China Sea and western North Pacific. J. Climate, 22, 47714792.

Mantua, N. J., S. R. Hare, Y. Zhang, J. M. Wallace, and R. C. Francis, 1997: A Pacific interdecadal climate oscillation with impacts on salmon production. Bull. Amer. Meteor. Soc., 78, 1069-1079.

Meehl, G. A., L. Goddard, J. Murphy, R. J. Stouffer, G. Boer, G. Danabasoglu, K. Dixon, M. A. Giorgetta, A. Greene, E. Hawkins, G. Hegerl, D. Karoly, N. Keenlyside, M. Kimoto, B. Kirtman, A. Navarra, R. Pulwarty, D. Smith, D. Stammer, and T. Stockdale, 2009: Decadal prediction: Can it be skillful?. Bull. Amer. Meteor. Soc., 90, 14671485.

Minobe, S., 1999: Resonance in bidecadal and pentadecadal climate oscillations over the North Pacific: Role in climatic regime shifts. Geophys. Res. Lett., 26, 855-858.

Minobe, S., 2002: Interannual to interdecadal changes in the Bering Sea and concurrent 1998/99 changes over the North Pacific. Progress in Oceanography, 55, 45-64.

Mochizuki, T., Y. Chikamoto, M. Kimoto, M. Ishii, H. Tatebe, Y. Komuro, T. T. Sakamoto, M. Watanabe, and M. Mori, 2012: Decadal prediction using a recent series of MIROC global climate models. J. Meteor. Soc. Japan, 90A, 373-383.

Mochizuki, T., M. Ishii, M. Kimoto, Y. Chikamoto, M. Watanabe, T. Nozawa, T. T. Sakamoto, H. Shiogama, T. Awaji, N. Suiura, T. Toyoda, S. Yasunaka, H. Tatebe, and M. Mori, 2010: Pacific decadal oscillation hindcasts relevant to nearterm climate prediction. Proc. Natl. Acad. Sci. USA, 107, 1833, doi:10.1073/pnas.0906531107.

Moss, R., M. Babiker, S. Brinkman, E. Calvo, T. Carter, J. Edmonds, I. Elgizouli, S. Emori, L. Erda, K. Hibbard, R. Jones, M. Kainuma, J. Kelleher, J. F. Lamarque, M. Manning, B. Matthews, J. Meehl, L. Meyer, J. Mitchell, N. Nakicenovic, B. O'Neill, R. Pichs, K. Riahi, S. Rose, P. Runci, R. Stouffer, D. van Vuuren, J. Weyant, T. Wilbanks, J. P. van Ypersele, and M. Zurek, 2008: Towards new scenarios for analysis of emissions, climate change, impacts, and response strategies. Tech. Rep., Pacific Northwest National Laboratory (PNNL), Richland, WA (US).

Moss, R. H., J. A. Edmonds, K. A. Hibbard, M. R. Manning, S. K. Rose, D. P. van Vuuren, T. R. Carter, S. Emori, M. Kainuma, T. Kram, G. A. Meehl, J. F. B. Mitchell, N. Nakicenovic, K. Riahi, S. J. Smith, R. J. Stouffer, A. M. Thomson, J. P. Weyant, and T. J. Wilbanks, 2010: The next generation of scenarios for climate change research and assessment. Nature, 463, 747-756.
Nakicenovic, N., J. Alcamo, G. Davis, B. de Vries, J. Fenhann, S. Gaffin, K. Gregory, A. Grubler, T. Jung, T. Kram, E. L. La Rovere, B. Metz, T. Morita, W. Pepper, H. Pitcher, A. Sankovski, P. Shukla, R. Swart, R. Watson, and Z. Dadi, 2000: Emissions Scenarios, A Special Report of Working Group III of the Intergovernmental Panel on Climate Change. Cambridge Univ. Press, New York.

Nitta, T., and S. Yamada, 1989: Recent warming of tropical sea surface temperature and its relationship to the Northern Hemisphere circulation. J. Meteor. Soc. Japan, 67, 375-383.

Nozawa, T., T. Nagashima, T. Ogura, T. Yokohata, N. Okada, and H. Shiogama, 2007: Climate change simulations with a coupled oceanatmosphere GCM called the model for interdisciplinary research on climate: MIROC. CGER Supercomput. Monogr. Rep., 12, cent. For Global Environ. Res., Natl. Inst. for Environ. Stud., Tsukuba, Japan.

Nozawa, T., T. Nagashima, H. Shiogama, and S. A. Crooks, 2005: Detecting natural influence on surface air temperature change in the early twentieth century. Geophys. Res. Lett., 32, L20719, doi:10.1029/2005GL023540.

Ose, T., Y. Song, and A. Kitoh, 1997: Sea surface temperature in the South China Sea: An index for the Asian monsoon and ENSO system. J. Meteor. Soc. Japan, 75, 1091-1107.

Pohlmann, H., J. H. Jungclaus, A. Köhl, D. Stammer, and J. Marotzke, 2009: Initializing decadal climate predictions with the GECCO oceanic synthesis: Effects on the North Atlantic. J. Climate, 22, 39263938, doi:10.1175/2009JCLI2535.1.

Robock, A., 2000: Volcanic eruptions and climate. Rev. Geophys., 38, 191-219.

Rowell, D., C. Folland, K. Maskell, and M. Ward, 1995: Variability of summer rainfall over tropical north Africa (1906-92): Observations and modelling. Quart. J. Roy. Meteor. Soc., 121, 669-704.

Sakamoto, T. T., Y. Komuro, M. Ishii, H. Tatebe, H. Shiogama, A. Hasegawa, T. Toyoda, M. Mori, T. Suzuki, Y. Imada-Kanamaru, T. Nozawa, K. Takata, T. Mochizuki, K. Ogochi, T. Nishimura, S. Emori, H. Hasumi, and M. Kimoto, 2011: MIROC4h-a new high-resolution atmosphere-ocean coupled general circulation model. J. Meteor. Soc. Japan, submitted.

Shiogama, H., S. Emori, T. Mochizuki, S. Yasunaka, T. Yokohata, M. Ishii, T. Nozawa, and M. Kimoto, 2010: Possible Influence of Volcanic Activity on the Decadal Potential Predictability of the Natural Variability in Near-Term Climate Predictions. $A d v$. Meteor., 2010, 7, doi:10.1155/2010/657318, article ID 657318 .

Shiogama, H., T. Nozawa, and S. Emori, 2007: Robustness of climate change signals in near term predic- 
tions up to the year 2030: Changes in the frequency of temperature extremes. Geophys. Res. Lett., 34, L12 714, doi:10.1029/2007GL029318.

Smith, D. M., S. Cusack, A. W. Colman, C. K. Folland, G. R. Harris, and J. M. Murphy, 2007: Improved surface temperature prediction for the coming decade from a global climate model. Science, 317, 796-799, doi:10.1126/science.1139540.

Soden, B. J., R. T. Wetherald, G. L. Stenchikov, and A. Robock, 2002: Global cooling after the eruption of Mount Pinatubo: A test of climate feedback by water vapor. Science, 296, 727.

Tanimoto, Y., K. Hanawa, Y. Toba, and N. Iwasaka, 1993: Characteristic variations of sea surface temperature with multiple time scales in the North Pacific. J. Climate, 6, 1153-1160.

Tatebe, H., and I. Yasuda, 2005: Interdecadal variations of the coastal Oyashio from the 1970s to the early 1990s. Geophys. Res. Lett., 32, L10 613, doi:10.1029/2005GL022605.

Tatebe, H., M. Ishii, T. Mochizuki, Y. Chikamoto, T. T. Sakamoto, Y. Komuro, M. Mori, S. Yasunaka, M. Watanabe, K. Ogochi, T. Suzuki, T. Nishimura, and M. Kimoto, 2012: The Initialization of the MIROC climate models with hydographic data assimilation for decadal prediction. J. Meteor. Soc. Japan, 90A, 275-294.

Timmermann, A., S. McGregor, and F.-F. Jin, 2010: Wind effects on past and future regional sea level trends in the southern Indo-Pacific. J. Climate, 23, 4429-4437, doi:10.1175/2010JCLI3519.1.

Trenberth, K., 1990: Recent observed interdecadal climate changes in the Northern Hemisphere. Bull. Amer. Meteor. Soc., 71, 988-993.
Tu, J., C. Chou, and P. Chu, 2009: The abrupt shift of typhoon activity in the vicinity of Taiwan and its association with western North Pacific-East Asian climate change. J. Climate, 22, 3617-3628.

Vecchi, G. A., B. J. Soden, A. T. Wittenberg, I. M. Held, A. Leetmaa, and M. J. Harrison, 2006: Weakening of tropical pacific atmospheric circulation due to anthropogenic forcing. Nature, 441, 73-76.

Watanabe, M., T. Suzuki, R. O'ishi, Y. Komuro, S. Watanabe, S. Emori, T. Takemura, M. Chikira, T. Ogura, M. Sekiguchi, K. Takata, D. Yamazaki, T. Yokohata, T. Nozawa, H. Hasumi, H. Tatebe, and M. Kimoto, 2010: Improved climate simulation by MIROC5: Mean states, variability, and climate sensitivity. J. Climate, 23, 6312-6335, doi:10.1175/2010JCLI3679.1.

Xu, B., J. Cao, J. Hansen, T. Yao, D. Joswia, N. Wang, G. Wu, M. Wang, H. Zhao, W. Yang, X. Liu, and J. He, 2009: Black soot and the survival of Tibetan glaciers. Proc. Natl. Acad. Sci., 106, 22114.

Yasuda, I., 2003: Hydrographic structure and variability in the Kuroshio-Oyashio transition area. $J$. Oceanogr., 59, 389-402.

Yasunaka, S., and K. Hanawa, 2002: Regime shifts found in the Northern Hemisphere SST field. $J$. Meteor. Soc. Japan, 80, 119-135.

Yokohata, T., S. Emori, T. Nozawa, Y. Tsushima, T. Ogura, and M. Kimoto, 2005: Climate response to volcanic forcing: Validation of climate sensitivity of a coupled atmosphere-ocean general circulation model. Geophys. Res. Lett, 32, L21 710, doi:10.1029/2005GL023542.

Zhang, Y., J. Wallace, and D. Battisti, 1997: ENSO-like interdecadal variability: 1900-93. J. Climate, 10, 1004-1020. 